\title{
¿LA REGLA DE DERECHO DEBE PREVALECER SOBRE EL PRINCIPIO JURÍDICO LABORAL? ANÁLISIS DEL CONTRATO ADMINISTRATIVO DE SERVICIOS
}

\author{
SHOULD THE RULE OF LAW PREVAIL OVER THE LABOR LEGAL \\ PRINCIPLE? ANALYSIS OF THE ADMINISTRATIVE \\ CONTRACT OF SERVICES.
}

\author{
Lizet Jackeline Zavala Van Oordt \\ Maestra en Derecho de Trabajo \\ Universidad de San Martín de Porres \\ ljzv@hotmail.com
}

\section{SUMARIO}

- Introducción

- El Estado como empleador

- El Derecho Laboral

- La dignidad humana y los valores democráticos

- Conclusiones

\section{RESUMEN}

La autora expone críticamente la problemática laboral del trabajador al servicio del Estado peruano sujeto al régimen del denominado Contrato Administrativo de Servicios (CAS) y tiene como objetivo determinar que, en materia laboral, el Estado aplica la regla de derecho haciéndola prevalecer sobre el principio jurídico, en perjuicio del trabajador, afectando así los principios y derechos laborales existentes en dicha relación laboral. Asimismo, tiene como propósito verificar que el Estado no reconoce al trabajador sujeto a dicho régimen laboral, el derecho al tiempo de servicios adquirido ni la protección contra el despido arbitrario, entre otros derechos. La investigadora concluye en que, a partir de la indebida prevalencia de la regla de derecho sobre el principio jurídico, el Contrato Administrativo de Servicios es inconstitucional por afectar principios y derechos laborales, por lo que plantea la modificación del régimen CAS para que se reconozcan todos los derechos laborales al trabajador estatal.

\begin{abstract}
The author critically exposes the labor problematic of the worker at the service of the Peruvian State subject to the regime of the socalled Administrative Service Contract (CAS) and aims to determine that, in labor matters, the State applies the rule of law making it prevail over the principle Legal, to the detriment of the worker, thus affecting the principles and labor rights existing in this employment relationship. Likewise, it has the purpose of verifying that the State does not recognize the worker subject to said labor regime, the right to the time of services acquired nor the protection against the arbitrary dismissal. The investigator concludes that, due to the undue prevalence of the rule of law over the legal principle, the Administrative Service Contract is unconstitutional because it affects principles and labor rights, so it raises the modification of the CAS regime so that all labor rights are recognized for the state worker.
\end{abstract}

\section{PALABRAS CLAVES}

Estado, Derecho, Principio jurídico, Regla normativa, Régimen laboral, Contrato administrativo de servicios.

\section{KEY WORDS}

State, Law, Legal principle, Regulation rule, Labor regime, Administrative contract of services. 


\section{INTRODUCCIÓN}

El artículo describe un aspecto singular de la realidad laboral en el sector público nacional, caracterizado por el hecho de que el Estado como empleador contrata personal, bajo subordinación y dependencia, bajo distintos regímenes regulatorios, $\mathrm{y}$ obviamente con diferentes derechos, para desempeñar la misma función de carácter permanente en la misma repartición pública y no obstante su carácter único e indivisible como organización jurídica y política de la sociedad, a la que obviamente pertenece dicho personal.

La autora considera dicha situación un grave problema, para cuyo planteamiento inicia el análisis con el estudio del Decreto Legislativo $\mathrm{N}^{\circ}$ 1057, que regula el régimen especial del Contrato Administrativo de Servicios (en adelante CAS), el cual establece en su artículo $5^{\circ}$ que dicho contrato se celebra a plazo determinado y es renovable. Asimismo, examina el Decreto Supremo No 075-2008PCM, que aprueba el Reglamento del Decreto Legislativo $\mathrm{N}^{\circ} 1057$, el cual dispone en su artículo $5^{\circ}$ que la duración de dicho contrato no puede ser mayor al periodo que corresponde al año fiscal respectivo dentro del cual se efectúa la contratación; sin embargo, el contrato puede ser prorrogado o renovado cuantas veces considere la entidad contratante en función de sus necesidades. Cada prórroga o renovación no puede exceder del año fiscal respectivo.

En el marco normativo de este nuevo tipo de contrato, la investigadora identifica la problemática inquiriendo si el Estado en el ámbito laboral de la administración pública protege al trabajador en sus derechos fundamentales de índole laboral; o acaso afecta dichos derechos que se sustentan en la dignidad humana, en la igualdad y en otros principios y valores democráticos; o si en este régimen CAS, el trabajador al servicio del Estado tiene estabilidad laboral futura.

Al respecto, la investigadora contrasta estas disposiciones normativas con el Principio de Continuidad, que se refiere al transcurso, mantenimiento y prolongación en el tiempo de la relación laboral, de manera continua, de tal modo que defiende la estabilidad en el empleo, procura evitar la transitoriedad y provisionalidad de los recursos humanos, que es un valioso capital de trabajo y, sobre todo, tiende a otorgar una protección del tiempo de servicios adquirido por el trabajador; funcionando de esta manera como una garantía para el trabajador; y perfila como problema si es razonable privar, limitar o restringir este principio.

Asimismo, la investigadora asevera que estas contrataciones sólo duran entre uno a tres meses, aunque pueden ser renovadas si la entidad lo cree necesario, pero sin sobrepasar el año fiscal respectivo; en este orden de ideas configura como problema si ¿se afecta el derecho a la estabilidad laboral futura y la carrera profesional pública o se propende al desconocimiento de las capacidades laborales, se desacredita y anula o se consagra la meritocracia, contrariamente a lo que dispone como finalidad el Decreto Legislativo $\mathrm{N}^{\circ} 1057$.

Además, la investigadora identifica determinadas situaciones problemáticas en la situación descrita, tales como, ¿este régimen especial respeta el fundamental derecho a la igualdad entre un trabajador sujeto al régimen CAS y un trabajador sujeto al régimen laboral del Decreto Legislativo $N^{\circ} 276$ o del Decreto Legislativo $\mathrm{N}^{\circ} 728$ ?; reflexionando sobre si deberían tener los trabajadores del Estado peruano los mismos derechos y beneficios laborales; y si el Estado peruano está obligado a respetar y promover los derechos humanos, conforme a lo dispuesto por los artículos $22^{\circ}$ y $23^{\circ}$ de la Constitución Política.

Por otro lado, delinea el problema de si ¿es razonable considerar a la situación expuesta como un tratamiento diferenciado, tratándose de servicios laborales incluso en la misma ocupación, función o cargo?; ¿si el Estado peruano con este régimen reconoce el derecho a la justa compensación por el tiempo de servicios trabajado, como lo hace con los demás contratos laborales a plazo determinado?; o si ¿se afecta el derecho a la protección contra el despido arbitrario?

A mayor abundamiento, se pregunta si ¿el hecho que la Ley $N^{\circ} 29849$ establezca la eliminación progresiva de este régimen especial, regulariza la indemnidad de los derechos laborales afectados?; ¿si el tiempo de vigencia del CAS $\mathrm{y}$ el índice de trabajadores públicos sujetos a dicho régimen, comprueba o descarta su eliminación gradual?; ¿si es razonable jurídicamente y es legítimo democráticamente 
que se constituya un régimen especial para que el Estado peruano contrate personal en condiciones diferentes a las que se encuentra el personal de servidores y funcionarios públicos; o si un régimen laboral especial se justifica constitucionalmente para el mismo fin?

La investigadora disiente de los fundamentos de la sentencia emitida por el Tribunal Constitucional, recaída en la demanda de inconstitucionalidad interpuesta por 5000 ciudadanos contra el Decreto Legislativo $\mathrm{N}^{\circ}$ 1057(STC $\mathrm{N}^{\circ}$ 00002-2010-PI/TC), en la que declara que el CAS es constitucional; y considera que crea confusión entre los operadores del derecho, situación que ha sido materia de esta investigación, evaluando el problema trascendental de la tensión entre la regla de derecho y los principios jurídicos inspirados en los valores incorporados por la filosofía y el sistema democrático que configuran un ordenamiento jurídico político.

Por ello, los objetivos del presente artículo son determinar la invalidez de una regla de derecho que transgrede los principios jurídicos, valores democráticos y derechos laborales en perjuicio de un trabajador estatal sujeto al Contrato Administrativo de Servicios; comprobar la afectación del Principio de Continuidad en el Contrato Administrativo de Servicios; evidenciar la devaluación de los mecanismos de tutela jurídica frente al despido injustificado (afectación al principio de causalidad) en el régimen del Contrato Administrativo de Servicios; acreditar la ausencia de la tutela restitutoria frente al despido arbitrario en la Contratación Administrativa de Servicios; demostrar la condición desigual a que está sujeto el servidor frente a un trabajador estatal sujeto a otro régimen laboral; señalar que los derechos de igualdad, estabilidad laboral, compensación por tiempo de servicios, gratificaciones, escolaridad, uniformes, asignación familiar, que tienen los trabajadores del Estado sujetos a otros regímenes laborales, son inobservados en el Contrato Administrativo de Servicios.

\section{EL ESTADO COMO EMPLEADOR}

\section{Concepto, origen y finalidad del Estado}

El Estado, según lo conceptúa Ferrero, R. (2003) es la simbiosis de la sociedad más el poder, es decir, una organización social y política, cuya entidad o ser deriva de la sociabilidad humana, de allí que el estado y la sociedad sean inseparables en la praxis, aun cuando se les separa conceptualmente. Como realidad objetivable, el Estado es obra del hombre, creada de acuerdo con la naturaleza social de éste. El Estado es un ser de derecho que compendia una colectividad humana que apunta a la unidad y homogeneidad del Estado, a través de sus tres elementos, pueblo, territorio y poder, más la finalidad que lo anima, es decir, el bien común. En ese sentido, el poder y el fin fundamentan el orden jurídico y político del Estado.

Heller, H. citado por Ferrero, R. (2003, página 45) sostiene que "el hombre es producto y a la vez productor de la historia. En la historia que se produce actúa la ya producida".

Por otra parte, Borea, A. (1994) afirma que desde un enfoque deontológico el Estado se explica por los fines que debe cumplir, por ejemplo la búsqueda de la libertad y la igualdad. La prosecución del bien común como fundamento esencial de la reunión de los seres humanos en un Estado, propio de la concepción aristotélico-tomista, es otro de los casos en los que se sostiene la existencia de la organización por el fin que se persigue.

A tal efecto, Uribe Gonzáles, citado por Borea, A. (1994) postula como definición ética del Estado, una organización total que establece y mantiene el orden jurídico en un territorio determinado; que está dotada de un poder supremo; y tiene el monopolio del poder físico coactivo para asegurar una unidad de decisión y acción, respetando y garantizando la estructura pluralista de la sociedad y persiguiendo fines valiosos

El Estado también es definido sociológicamente como una sociedad políticamente organizada alrededor de un centro de poder que se extiende sobre un territorio determinado, como apunta Raúl Ferrero y Alberto Borea (1994).

También existen definiciones jurídicas del Estado. De acuerdo con Borea, A. (1994) son aquellas que definen al Estado por su función jurídica, que es la esencia misma del ser del Estado, por lo que no hay Estado sin derecho, y que éste es el orden que aquel personifica para una más fácil aprehensión de lo que en realidad el derecho vendría ser un concepto abstracto.

Del Vecchio, G. citado por Borea, A. (1994) sostiene que el Estado es el módulo integrado 
de un sistema jurídico que tiene en sí mismo el propio centro autónomo; y que está provisto de la suprema cualidad de persona en sentido jurídico.

Por su parte, Kelsen, H (1969) señala que el Estado es la comunidad creada por un orden jurídico nacional; siendo como persona jurídica la personificación de dicha comunidad.

El Estado es, sin duda, una unidad sociológica, esto es, una comunidad social o pluralidad de individuos, no solo una entidad jurídica, sino una realidad social independiente del orden jurídico.

El Estado también puede ser visto como una relación en virtud de la cual alguien manda y gobierna y otros obedecen y son gobernados, en virtud de un pacto social y político.

Entre los conceptos jurídico y sociológico del Estado, en opinión de la investigadora, el primero no puede dejar de considerar que la organización estatal es un hecho soberanamente real, mientras que la acepción jurídica es fruto de una interpretación. El Estado es el resultado de acciones humanas, de ahí que sea una creación y una actividad humana, por lo que la realidad natural es el hombre y constituye el fin supremo de la realidad artificial que es el Estado.

Como se puede apreciar de los pensamientos de los autores citados, el Estado es la organización jurídica y política de una sociedad, para cumplir fines comunes en beneficio del conjunto de sus miembros, de tal modo de realizar el bien común para alcanzar la paz social a través del Derecho. En este concepto apreciamos el carácter sociológico, deontológico y jurídico de dicha organización humana, creada por el hombre para procurarse bienestar general y seguridad integral.

De este concepto tripartito, fuerza es deducir que el hombre crea el Estado para procurarse una vida mejor en orden a la satisfacción de sus necesidades comunes y la solución de sus problemas colectivos. Esta es una razón de supervivencia, dada la naturaleza gregaria y social del ser humano, que no puede subsistir si no es en comunidad, debido al rasgo de sociabilidad que le es ínsito y que deriva del rasgo de mundanidad que le es connatural, pues al estar dotado de inteligencia, libertad y voluntad, es consciente de que es y está en el mundo, en un espacio-tiempo histórico determinado; para de allí tomar consciencia de que con él están otros hombres en el mismo espacio-tiempo histórico, que es el rasgo de sociabilidad.

Una vez situado el ser humano en dicho nivel de conciencia ontológica y relacional, se identifica un tercer nivel de conciencia connatural, que es el de la politicidad, por el cual el hombre toma conciencia de que solo puede subsistir si se asocia con sus semejantes para vivir organizados y de esa manera proveer mejor a su subsistencia, lo que significa bienestar general y seguridad integral.

En estos conceptos se puede resumir la gnoseología y epistemología del Estado, como instrumento vital para el hombre, de donde se colige que resulta contradictorio con la esencia y finalidad del Estado, bajo cualquier ideología, una actividad de éste contraria a la dignidad y derechos naturales y fundamentales del hombre. Lo cual incluye, naturalmente, al Derecho positivo, como conjunto de normas creadas por el Estado para regular la convivencia humana en su territorio, las cuales deben inspirarse en los principios y derechos inmanentes, que son anteriores y superiores al Estado, por pertenecer y corresponder a la naturaleza humana, que es originaria y no accidental como lo es el Estado, por lo que la persona humana es incuestionablemente un fin en sí mismo, a diferencia del Estado que es un medio para la realización y trascendencia del hombre.

En el mismo sentido, es importante subrayar que el poder que los hombres delegan en el Estado, como lo enseñan la ciencia política y la cratología, debe seguir el fin del otorgamiento de dichas atribuciones, que no es otro que el de ser un instrumento de servicio al hombre individual $\mathrm{y}$ colectivamente considerado. Ergo, no es razonable sostener que el poder puede tener otro fin distinto $\mathrm{y}$, menos aún, contrario al hombre, no obstante saber que, como capacidad psico, bio, espiritual para imponer la voluntad a los demás, y de acuerdo con la falible naturaleza humana, tiende a inclinarse a ser usado en el propio beneficio de quien lo detenta legítima o ilegítimamente; sin embargo, esto con ser objetivo y comprobable, no enerva ni desvirtúa la apreciación finalista del Estado, que solo puede ser conducido mediante el poder político, pues la eventual 
Should the rule of law prevail over the labor legal principle?

Analysis of the administrative contract of services.

desnaturalización del ejercicio del poder, no obsta para extinguir el principio en el que se basa y para el cual existe, cual es, el de hacer posible la trascendencia del ser humano.

Como se ve, es reiterativa en la existencia humana la dicotomía entre lo que debe ser y lo que es; entre principios y realidad; debido a las manifestaciones no pacíficas ni unívocas del poder. Esta contradicción sirve, más bien, para reforzar las esencias y finalidades, vencer las pasiones y ambiciones, enderezar desvaríos y reencauzar los auténticos fines del Estado.

Este es, entonces, un punto no negociable en la comprensión de la problemática que comporta la administración del Estado en orden al diseño de políticas públicas de planteo de soluciones de los problemas humanos bajo su soberanía y jurisdicción. Y lo es porque resulta una verdadera antinomia considerar que teniendo el Estado tal finalidad ministerial, servicial, instrumental y tributaria respecto del hombre, pueda administrar la cosa pública que a éste le compete por naturaleza, en contra de su beneficio, privándolo de atribuciones que aquel no le ha concedido, sino simplemente reconocido, por exigencias éticas y conquistas populares históricas.

Borea, A. (1994) sostiene que el Estado se inicia cuando convergen y se definen sus elementos básicos, como son el poder, el pueblo y el territorio, como consecuencia del progreso cultural de una sociedad, corolario de la unión nacional de su población, que ha buscado la autodeterminación y el autogobierno, creando sus propios mecanismos de poder y asentándose en un territorio.

La denominación estado es moderna y corresponde a la unión política alcanzada con posterioridad a la Edad Media. Anteriormente, la palabra polis para los griegos, expresaba la comunidad diferenciada por una forma de vida propia. Para los romanos, la res pública, la civitas y el imperium, eran denominaciones de su organización política, con las que enfatizaban el concepto estado, como potestad de mandar. De la misma manera, en Germania también se remarcó el elemento de dominio con la voz Reich, voz que procede de regmun que significa mando de un príncipe, como apunta Ferrero, R. (2003), quien recuerda que la denominación estado fue utilizada por primera vez por Maquiavelo, en su obra el Príncipe. La palabra stato derivada de la voz latina status expresa un orden y responde a una necesidad general, con independencia de las formas, sean republicanas, monárquicas o tiránicas,

El origen del Estado para el mismo autor, consiste en identificar su esencia y finalidad, que es sociológica y filosófica, respectivamente, y que deben ser realizadas a través del derecho positivo, que vendría a ser el vehículo para alcanzar el fin del Estado y no como sostiene el positivismo, al que le preocupa la primacía de la regla jurídica.

El Estado tiene raíz sociológica y, en esa medida, responde como agrupación humana a un impulso natural, que se mantiene en su existencia y desarrollo gracias a la voluntad de su población, la cual lo rehace y construye plebiscitariamente en su devenir histórico. Al respecto, Carré de Malberg (1999) sostiene sobre la génesis del estado que la formación originaria de los estados no puede ser deducida de un acto jurídico, ya que el derecho es una creación estatal posterior $\mathrm{y}$, por eso mismo, no puede ser aplicado a la formación misma del Estado.

Como se puede apreciar, el origen del Estado refuerza su concepto en la medida que surgido de un acto humano voluntario de fuerza o de consenso, busca mediante el poder que le confieren sus fundadores, organizar la colectividad asentada en un territorio para garantizarle subsistencia de un modo mejor que si fuera segmentada, de ahí que la organización política que emplea el poder y en ese ejercicio produce derecho, lo debe hacer con la finalidad de atender las necesidades colectivas.

En nuestro juicio, la idea de una forma organizativa de índole política primero, que hoy conocemos bajo el nombre de estado, le es dada al hombre por su naturaleza gregaria y por sus instintos de mundanidad, sociabilidad y politicidad. En esta idea originaria se encuentra comprendida la finalidad de la organización, que es la subsistencia social de la mejor manera posible. Para ello, esa forma organizativa política, produce derecho positivo, esto es, reglas y normas para regular la vida social con miras al logro del fin, las metas y objetivos de la formación social de hombres. Por esta vía de análisis también se llega al convencimiento de que aun el derecho positivo creado por el estado debe seguir el principio meta jurídico 
y natural, que es anterior y superior a la organización política, ya que apunta a alcanzar el fin que anima a la colectividad organizada.

Puede que para la teoría pura del derecho no le concierna desarrollar ni resolver el tema de la preeminencia del principio axiológico natural sobre la regla jurídica, porque su afán no es causalista respecto al origen de la organización política sino meramente funcionalista, pero aun así, en el plano de la función tampoco nos parece factible escapar del destino finalista del órgano estructurado ad hoc, pues la creación toda del aparato estatal obedece a una razón funcional que solo encuentra viabilidad legítima en el apego a los principios y valores que inspiraron su origen y nacimiento.

La causa final del Estado es el bien común, es decir, el bien de la comunidad, a la cual se llega mediante las condiciones dadas por el orden jurídico, que integra el poder y la finalidad del Estado. El poder dicta el orden y la finalidad del Estado está más allá de aquel, pues lo inspira, como señala Ferrero, R. (2003), quien recuerda que el Estado está creado para la persona humana. Ambos tienen deberes correlativos que no pueden recusar. El Estado realiza valores, tales como la libertad, la igualdad, la seguridad jurídica y la justicia, que el hombre no podría alcanzar por sí solo. Ahora bien, no debe confundirse la organización del estado con la estructura del gobierno, sin embargo, hay que reconocer que la forma de estado influye en la forma de gobierno, como ocurre en los casos de federación. El gobierno formula la voluntad del Estado, que es la organización del poder.

El Estado es una agrupación jerarquizada compuesta por asociados iguales, de los que se elige a los gobernantes como servidores de la comunidad, por lo que no pueden ejercer de manera desviada o extralimitada el poder que la sociedad les da. El poder conferido por el pueblo a los gobernantes elegidos de su propio seno, debe respetar y garantizar los derechos fundamentales del hombre para ser democrático; y no debe negarlos, desconocerlos o restringirlos arbitrariamente, pues sería autoritario o totalitario.

Por otro lado, para Bidart, G. (2002) el Estado es democrático cuando su poder, en la relación con los hombres que forman su población, ejerce en forma respetuosa respecto de aquella situación personal debida al hombre por imperio de la justicia.

De tal modo que, también desde el enfoque finalista, la regla jurídica debe subordinarse al principio natural axiológico, dado que es simultáneamente su causa y finalidad en cualquier clase de estado, bajo cualquier ideología. De hecho, todo estado aspira al bien común de sus integrantes. La noción de bien común es un ideal por alcanzar y es perfectible en el transcurso del tiempo debido a la dinámica de la vida misma. Ese ideal es formado ideológicamente y así tenemos que en unos estados el camino para llegar al bien común será la igualdad absoluta de todos los miembros, mientras que en otros lo será la libertad.

Sin embargo, ese ideal común para el cual se crea el estado, como es el alcanzar el bien común, que se traduce en bienestar genera y seguridad integral, tiene su significación distinta en el orden jurídico positivo estatal. Así, en un régimen de igualdad absoluta la normatividad reflejará esta paridad en la equivalencia de todo para todos. En cambio, en un régimen de libertad, las normas jurídicas preferirán la independencia y el albedrío, con lo cual detonarán la desigualdad, lo que provocaría que haya igualdad y libertad solo para algunos, con lo cual el principio inmanente de la dignidad humana se resquebrajaría.

Lo anterior no significa que en la tensión entre principio y norma, no se pueda excepcionalmente restringir o limitar, mediante la regla jurídica, algún derecho fundamental, pero ello será posible si y solo si tal medida contribuye al logro de la finalidad común, es decir, su razonabilidad estará condicionada a la congruencia que muestre respecto a una mejor regulación para hacer óptima la vida social; y no al aprovechamiento de unos en perjuicio de otros, como tampoco a la negación pura y simple del derecho natural por motivos baladíes, ya que en tal caso la discriminación haría su aparición en contra del principio de igualdad, siendo irrazonable por atentar contra la naturaleza humana. Esa eventual limitación del principio por una regla jurídica, tendría que ser no solo excepcional y temporal, sino además tendría que estar fundada en condiciones objetivas determinantes y trascendentes, no en circunstancias subjetivas. 
Análisis del contrato administrativo de servicios

Should the rule of law prevail over the labor legal principle?

Analysis of the administrative contract of services.

\section{El empleador en una relación laboral}

El laboralista Toyama, J. (2008) señala en términos generales que el contrato de trabajo es un acuerdo de voluntades entre el trabajador y el empleador para la prestación de servicios personales y subordinados, lo cual significa que es un negocio jurídico mediante el cual un trabajador presta servicios personales por cuenta ajena para un empleador, en una relación de subordinación a cambio de una remuneración.

Carrasco y Torres (2006) mencionan que, según Francisco de Ferrari, se define corrientemente el contrato de trabajo como aquel por el cual una persona se obliga a trabajar por cuenta y bajo la dependencia de otra o a estar simplemente a sus órdenes, recibiendo como compensación una retribución de dinero.

Cabanellas, G. (1982) afirma que el contrato de trabajo es aquel que tiene por objeto la prestación continuada de servicios privados y con carácter económico, por cual una de las partes da una remuneración o recompensa a cambio de disfrutar o de servirse, bajo su dependencia o dirección de la actividad profesional de otra.

Son tres los elementos esenciales del contrato de trabajo, dependiendo de su presencia en conjunto para definirlo, de lo contrario será otro tipo de relación jurídica, más no laboral. La prestación laboral de servicios, la subordinación y la remuneración son los elementos esenciales que tipifican y definen un contrato de trabajo.

Neves, J. (2000) sostiene acerca de la prestación personal que esta relación laboral tiene como objeto del contrato de trabajo la actividad específica de un trabajador determinado. De aquí se deriva, en primer lugar, que el trabajador es siempre una persona natural a diferencia del empleador que puede que puede ser una persona natural (como en el hogar o los pequeños negocios) o jurídica y adoptar cualquier forma asociativa, lucrativa o no.

Carrasco y Torres (2006) acerca de la presunción de existencia de contrato de trabajo en el artículo $4^{\circ}$ del Texto Único Ordenado de la Ley de Productividad y Competitividad Laboral, aprobado por DS. $\mathrm{N}^{\circ}$ 003-97-TR, establece la situación de presunción de la existencia de un contrato de trabajo. Dicha norma señala que en toda prestación de personal de servicios remunerados y subordinados se presume la existencia de un contrato de trabajo a plazo indeterminado. De hecho, cuando se dan esas características más importantes, para muchos, es definitivo que permite identificar la existencia de una relación laboral. Pero según la norma, no solo se presume la existencia de un contrato de trabajo cuando se presentan las características mencionadas, sino que se presume también que ese contrato es a plazo indeterminado. En cualquiera de los casos, la presunción admite prueba en contario; para tal efecto deberá probarse fehacientemente que no se trata de un contrato de trabajo o, en caso de serlo, podrá probarse que no se trata de un contrato indeterminado.

Respecto de la subordinación, Carrasco y Torres (2006) sostiene que es el elemento principal que sirve para determinar la verdadera naturaleza jurídica de las prestaciones de servicios es decir para distinguir si se trata de un contrato de trabajo o de una locación de servicio.

Cabanellas, G. (1972) reconoce que definir el estado de subordinación es uno de los problemas más difíciles y en relación al cual se encuentra más dividida la doctrina. Sin embargo, formula la siguiente definición:

Subordinación es el estado de limitación de la autonomía del trabajador al cual se encuentra sometida en sus prestaciones por razón de su contrato; y que proviene de la potestad del patrono o empresario para dirigir la actividad de la otra parte, en orden al mayor rendimiento de la producción y al mejor beneficio de la empresa.

Para Carrasco y Torres (2006) la subordinación tiene características, las mismas que se mencionan en el artículo $9^{\circ}$ de la Ley de Productividad y Competitividad Laboral, tales como, la facultad de normar reglamentariamente las labores; la facultad de dictar las órdenes necesarias para la ejecución de las mismas; y la facultad de sancionar disciplinariamente.

Consideramos que las primeras facultades mencionadas se refieren a la facultad de dirección. A estas se añaden, conforme a la doctrina, la facultad de control y sanción. Si el empleador ejercita estas tres facultades frente a sus trabajadores, no hay duda que se trata de 
un contrato de trabajo, pues ellas nos indican que existe subordinación en la prestación de servicios.

Neves, J. (2000) define la subordinación como un vínculo jurídico entre el deudor y el acreedor de trabajo, en virtud del cual el primero ofrece su actividad al segundo y le confiere el poder de conducirla. Sujeción, de un lado y dirección del otro, son los aspectos centrales del concepto. La subordinación es una característica propia del contrato de trabajo (art. 4 de la Ley de Productividad y Competitividad Laboral), ya que en las prestaciones de servicios reguladas por el Derecho Civil existe autonomía en los contratos de locación de servicios y de obra, según los artículos 1764 y 1771 del Código Civil respectivamente.

De modo similar define la subordinación el artículo 9 de la Ley de Productividad y Competitividad Laboral; el empleador puede pues impartir instrucciones, tanto de forma genérica mediante reglas válidas para toda la empresa o parte de ella (incorporadas comúnmente al reglamento interno de trabajo), como de forma específica, destinadas a un trabajador concreto, verificar si se cumplen adecuadamente o no, y en caso de constatar una inobservancia imputable al trabajador, sancionar a este por ello. Al desempeñar su poder de dirección el empleador debe moverse dentro de determinados marcos, fuera de los cuales incurre en ejercicio irregular de su derecho. El trabajador lo ha facultado para disponer de su actividad, no de su propia persona, razón por la cual las atribuciones del empleador deben ceñirse a la utilización de dicha actividad, dentro de los límites del ordenamiento laboral, sin afectar los derechos fundamentales del trabajador.

Para el laboralista Toyama, J. (2011) la subordinación o dependencia es el vínculo de sujeción que tienen el empleador y el trabajador en una relación laboral. De dicho vinculo surge el poder de dirección este poder e dirección implica la facultad del empleador de dirigir, fiscalizar y cunado lo crea conveniente, poder sancionar al trabajador dentro de los criterios de razonabilidad. Este es el elemento distintivo que permite diferenciar al contrato de trabajo del contrato de locación de servicios (en estos contratos, los servicios son autónomos o independientes).
Sobre el concepto de remuneración, Toyama, J. (2011) sostiene que es el integro de lo que el trabajador recibe por sus servicios como contraprestación, en dinero o en especie, cualquiera sea la forma o denominación que se le dé, siempre que sea de su libre disposición.

Neves, J. (2000) indica que tanto el contrato de trabajo como los de locación de servicios y de obra se ocupan de trabajados productivos por cuenta ajena. Esto quiere decir que el deudor ofrece su trabajo a un tercero y se convierte en el titular de lo que este produce, a cambio del pago de una retribución. La retribución otorgada en el contrato de trabajo se denomina remuneración nuestro ordenamiento laboral considera como tal al integro de lo que el trabajador recibe por sus servicios, en dinero o en especie, siempre que sea de su libre disposición.

De esta definición nos interesa resalta dos aspectos: el carácter contraprestacional y los bienes en que se materializa la remuneración. La remuneración tiene carácter contraprestacional pero no se agota en este. En otras palabras, es el pago que corresponde al trabajador por poner su actividad a disposición del empleador.

Carrasco y Torres (2006) definen como remuneración la obligación del empleador de retribuir el servicio del trabajador recibe diversas denominaciones, así tenemos que específicamente se denomina en doctrina sueldo a la remuneración de los trabajadores pagados mensualmente o quincenalmente; salario cuando se trata de remuneraciones pagadas en intervalos más cortos, semanales o diarios y jornal se aplica al salario fijado por cada día de trabajo.

Asimismo, hacen mención que el artículo $6^{\circ}$ de la Ley de Productividad y Competitividad Laboral, modificado por el art. $13^{\circ}$ de la Ley $\mathrm{N}^{\circ} 28051$, "constituye remuneración para todo efecto legal el integro de lo que el trabajador recibe por sus servicios, en dinero o en especie, cualquier sea la forma o denominación que tenga, siempre que sea de su libre disposición. Las sumas de dinero que se entreguen al trabajador directamente en calidad de principal como desayuno, almuerzo o refrigerio que lo sustituya o cena tienen naturaleza remunerativa. No constituye remuneración computable para efectos de cálculo de los aportes y contribuciones a la seguridad social 
Should the rule of law prevail over the labor legal principle?

Analysis of the administrative contract of services.

así como para ningún derecho o beneficio de naturaleza laboral el valor de las prestaciones alimentarias otorgadas bajo la modalidad de suministro indirecto. El concepto de remuneración descrito es aplicable para todo efecto legal cuando sea considerado como base de referencia ya sea para determinar los beneficios sociales o los tributos que gravan a las remuneraciones con la única excepción del impuesto que gravan la única excepción del impuesto a la renta que se rige por sus propias normas, conforme lo señala el art. $10^{\circ}$ del Reglamento del D. Leg. $\mathrm{N}^{\circ} 728$ aprobado mediante D.S Nº01-96-TR.

Respecto a los conceptos que no tiene carácter remunerativo, el Art. $7^{\circ}$ de la Ley de Productividad laborales y Competitividad Laboral aprobado por D.S $\mathrm{N}^{\circ}$ 003-97-TR dispone que " no constituye remuneración para ningún efecto legal los conceptos previstos en los artículos 19 y 20 del Texto único ordenado del Decreto Legislativo $\mathrm{N}^{\circ}$ 650". Dichos conceptos no tienen carácter remunerativo para ningún efecto legal cuando sea considerado como base de referencia, con las excepciones del Impuesto a la Renta que se rige por sus propias normas.

Según Toyama, J. (2011) los beneficios sociales legales son todos aquellos que perciben los trabajadores con ocasión de sus labores prestadas de manera dependiente. No importa su carácter remunerativo, el monto o la periodicidad del pago, pues lo relevante es lo que percibe el trabajador por su condición de tal y por mandato legal.

Nuestro ordenamiento prevé para los trabajadores seis beneficios económicos de origen legal que se abonan durante la relación laboral son los siguientes:

Las gratificaciones por fiestas patrias $y$ navidad: son aquellas sumas de dinero que el empleador otorga al trabajador en forma adicional a la remuneración que percibe mensualmente y siempre que cumpla con los requisitos correspondientes. En ese sentido los trabajadores sujetos al régimen laboral de la actividad privada tiene derecho de percibir dos gratificaciones, equivalentes a una remuneración mensual: una con motivo de fiestas patrias y otra con motivo de navidad. Las gratificaciones deberán ser abonadas en la primera quincena de los meses de julio y diciembre.
La asignación familiar, es un beneficio mensual otorgado a los trabajadores del régimen laboral de la actividad privada cuyas remuneraciones no se regulan por negociación colectiva, cualquier fuere su fecha de ingreso, su finalidad es contribuir a la manutención de los hijos menores, con independencia del número de hijos este beneficio asciende al diez por ciento mensual de la remuneración mínima vital vigente.

La bonificación por tiempo de servicios: es un complemento remunerativo que recompensa el mayor tiempo de servicios prestados por los trabajadores empleados $\mathrm{u}$ obreros comprendidos en el régimen laboral de la actividad privada. Esta bonificación es un reconocimiento a la antigüedad laboral de los servicios prestados para una sola empresa.

Esta bonificación a la fecha es un beneficio cerrado pues se otorga solamente para aquellos trabajadores que hasta el 29 de julio de 1995 cumplían 30 años de servicios para un solo empleador. Todos aquellos trabajadores que cumplen el tiempo de servicios exigido por la norma derogada luego del 29 de julio de 1995 ya no tienen derecho a este beneficio. Hay entonces un reconocimiento de los derechos adquiridos a favor de los trabajadores que ya venían gozando de este beneficio.

Beneficios sociales legales no remunerativos:

Los conceptos que consideran beneficios remunerativos son: El seguro de vida, CTS y las diversas formas de participación de los trabajadores, son beneficios legales no remunerados. El seguro de vida conjuntamente con la CTS son beneficios que tienen fines previsionales en la medida que buscan que los trabajadores y sus beneficiarios cuenten con una protección ante una contingencia desfavorable que pudiera acontecerles. Las utilidades constituyen el único beneficio legal cuya posibilidad de otorgarse resulta contingente; tienen múltiples aspectos que lo comprenden, tales como las formas en que puede darse la participación laboral de los trabajadores, los empleadores comprendidos, los requisitos y pautas de percepción, el fondo de capacitación y Promoción del Empleo, entre los más importantes.

El beneficio de la póliza de seguro de vida consiste en una obligación económica 
que contrae el empleador en favor de los beneficios de los trabajadores para cubrir las contingencias que se deriven del fallecimiento o invalidez permanentes estos. En ese sentido no nos encontramos ante un concepto remunerativo en la medida que este beneficio tiene por finalidad indemnizar a los familiares directos del trabajador que fallece durante la relación laboral o a los propios trabajadores se quedaran en invalidez permanente o total.

La participación laboral: Las utilidades. Es un derecho de los trabajadores reconocido constitucionalmente en los siguientes términos "El Estado reconoce el derecho de los trabajadores a participar en la utilidades de la empresa y promueve otras formas de participación", y que tiene por objeto de alguna manera acceder a las utilidades netas que percibe el empleador como consecuencia de su gestión empresarial. En este caso encontramos ante conceptos aleatorios que se perciben en función a la actividad empresarial.

La Compensación por tiempo de Servicios es el beneficio social más característico de nuestro ordenamiento laboral; constituye un elemento de previsión de las contingencias que origina el cese en el trabajo para el trabajador y su familia (es una suerte de seguro de desempleo financiado por las empresas y que se deposita semestralmente en la entidad financiera elegida por el trabajador). Tienen derecho a percibirla todos los trabajadores sujetos al régimen laboral de la actividad privada, que cumplan cuando menos en promedio una jornada ordinaria de cuatro horas diarias. En los casos en que la jornada semanal del trabajador, dividida entre seis o cinco días según corresponda, resuelto en promedio de no menor de cuatro horas, el requisito a que se refiere el párrafo anterior se considerara cumplido cuando el trabajador labore veinte horas a la semana como mínimo.

\section{Regimenes laborales del Sector Público}

\section{Contrato de Trabajo del Régimen Público. Decreto Legislativo $N^{\circ} 276$}

La carrera administrativa es una institución social que permite a los ciudadanos ejercer el derecho y el deber de brindar sus servicios a la Nación asegurando el desarrollo espiritual, moral, económico, y material del servidor público, a base de méritos y calificaciones en el desempeño de sus funciones y dentro de una estructura uniforme de grupos ocupacionales y de niveles.

Asimismo, se define como el conjunto de principios, normas y procesos que regulan el ingreso los derechos y los deberes que corresponden a los servidores públicos que con carácter estable prestan servicios de naturaleza permanente en la Administración Pública.

El artículo 1 del Título Preliminar de la Ley de bases de la Carrera Administrativa y de Remuneraciones del sector público, señala que la carrera administrativa tiene por objeto permitir la incorporación de personal idóneo, garantizar su permanencia, asegurar su desarrollo y promover su realización personal en el desempeño de servicio público.

La norma regula en el artículo $12^{\circ}$ que el ingreso a la Carrera Administrativa es mediante presentación y aprobación del concurso de admisión, habiendo cumplido previamente los requisitos de ser ciudadano peruano en ejercicio, buena conducta y salud, atributos del grupo ocupacional y demás que señalen las leyes.

También regula la promoción y ascenso de servidor de la carrera y posibilitaba que el servidor contratado pudiera ingresar a la carrera pública previa evaluación y bajo condición de que existiera plaza vacante con el beneficio de que le reconocían la antigüedad y tiempo de servicios prestados como contratado.

Además, de acuerdo a ley la carrera pública se rige por los principios de igualdad de oportunidades, estabilidad, garantía del nivel adquirido, retribución justa y equitativa, rigiéndose esta última por principios de universalidad, base técnica, relación directa con la carrera y adecuada compensación económica.

En lo que se refiere a las obligaciones, prohibiciones y derechos previstos en el artículo $21^{\circ}$, así como el régimen disciplinario, estos alcanzan a todos los servidores públicos con independencia si son de carrera o contratados. Las obligaciones están referidas al cumplimiento de las funciones, proteger los intereses del Estado, emplear austeramente los recursos públicos, cumplimiento del horario y puntualidad, conocimiento, capacitación buen trato al público, superiores y compañeros de trabajo, así como los deberes 
de confidencialidad y reserva y deberes de informar actos delictuoso de inmoralidad cometidos en ejercicio de la función pública.

Los derechos y beneficios de los trabajadores del sector público son similares con los del sector privado, en cuanto al pago de una remuneración mensual y periódica, sin embargo, el monto de las remuneraciones es regulada por ley y de acuerdo a escala remunerativa.

Dicho régimen laboral tiene derecho al pago de gratificaciones de fiestas patrias y navidad, así como el bono por escolaridad, pero a diferencia del sector privado, todos los trabajadores públicos no reciben un sueldo por dichos conceptos, sino el monto fijados por ley; a diferencia del sector privado que las remuneraciones las fija directamente el empleador con el derecho del trabajador que las misma sea integrada por todo pago periódico y de libre disposición que perciba el trabajador. Gozan del derecho a un mes de vacaciones por año de labor cumplido. Derecho a huelga y sindicalización, está permitido para la generalidad de trabajadores del sector público pero se restringe para algunos funcionarios y según tipo de actividad esencial para el Estado.

Asimismo, gozan de estabilidad laboral, pudiendo ser el personal cesado o destituido solo por causa prevista por ley y previo procedimiento disciplinario. Además se encuentran protegidos contra el despido injustificado y el despido nulo.

\section{Contrato de Trabajo del Régimen Privado. Decreto Legislativo $N^{\circ} 728$}

Pertenece al ámbito del sector privado para regular las relaciones jurídicas laborales de los trabajadores que prestan servicios para empleadores particulares. Este régimen laboral fue introducido en el sector público donde subsiste $\mathrm{y} / \mathrm{o}$ coexiste con el régimen del Decreto Legislativo $\mathrm{N}^{\circ} 276$. En la realidad laboral es la situación de la generalidad de las entidades públicas (como en el caso de las Municipalidades que tiene empleados y funcionarios en el régimen público, y obreros como los denominados trabajadores municipales en el régimen privado; en igual forma en varias entidades públicas como en el caso de las universidades nacionales, ministerios e incluso el Poder Judicial, en donde coexisten laboralmente personal de los dos regímenes diferentes) salvo excepciones muy limitadas y casos donde se aplican regímenes específicos como por ejemplo los docentes del sector educación).

Este tipo de contratación solo admite la prestación de servicios en forma personal y directa del trabajador, estableciendo el artículo $5^{\circ}$ del Decreto Legislativo $N^{\circ} 728$ que "los servicios para ser de naturaleza laboral, deben ser prestados en forma personal y directa sólo por el trabajador como persona natural".

El Contrato de trabajo de este régimen se caracteriza por la prestación de servicios remunerados bajo relación de dependencia y subordinación- artículo 4 Decreto Supremo $\mathrm{N}^{\circ}$ 003-97-TR (a diferencia de la locación de servicios donde no existe el carácter dependiente ni subordinado) y la excepción es la temporalidad, por lo que la norma presume en toda prestación de servicios remunerados y subordinados un contrato de trabajo por tiempo indeterminado.

El contrato a plazo indeterminado no tiene un término definido en razón de la naturaleza de las labores y la continuidad del servicio, a diferencia del contrato a plazo determinado que es temporal pudiendo ser a tiempo parcial o sujeto a modalidad; ambos están en relación a las condiciones contractuales será parcial cuando la prestación de servicios se efectúa por una jornada laboral menor a las horas, y será modal por la relación con aspectos subyacentes al contrato de trabajo.

Para Carrasco, L. y Torres (2006) hay dos tipos de contratos de trabajo respecto a su duración, estos son a plazo indeterminado y a plazo determinado.

El contrato de trabajo a plazo indeterminado es el tipo de contrato que se presume en toda prestación personal de servicios remunerados y subordinados, es decir cuando no pueda probarse la existencia de un contrato a plazo fijo, se entenderá que el contrato ha sido celebrado necesariamente por tiempo indeterminado. Este tipo de contrato puede celebrase en forma verbal o en forma escrita, indistintamente, pero deberá entenderse que dicho contrato prescritas en el TUO del Decreto Legislativo $\mathrm{N}^{\circ} 728$. Si bien ya no existe estabilidad laboral para este tipo de trabajadores, sin embargo, existe la protección contra el despido arbitrario. 
No existe obligación del empleador de poner en conocimiento de la Autoridad Administrativa de Trabajo la celebración de este tipo de contrato.

El contrato de trabajo a plazo determinado: Este tipo de contrato se le llama también contrato de trabajo sujetos a modalidad. La duración de estos contratos tiene fecha de terminación y pueden ser celebrados bajo cualquiera de las modalidades de contratos que permite el D. Leg. $\mathrm{N}^{\circ}$ 728. Los trabajadores que están bajo este tipo de contratos gozan también de protección contra el despido arbitrario; en consecuencia el empleador que resuelve el contrato unilateralmente deberá pagar una indemnización. Este tipo de contrato debe celebrarse necesariamente por escrito y en los casos que la ley permite.

\section{Contrato de trabajo en Régimen de tiempo parcial}

La ley permite la posibilidad de celebrar contratos de trabajo en régimen de tiempo parcial, sin limitación alguna. El régimen de tiempo parcial significa que la jornada diaria de trabajo debe ser menor de cuatro horas, pero no igual o mayor. Cuando la ley señala que este tipo de contratos puede celebrase sin limitación alguna se refiere a que la duración del contrato puede pactarse por tiempo indeterminado o por tiempo determinado, indistintamente.

\section{El régimen laboral especial del Contrato Administrativo de Servicios}

Para Quispe, G(2010) el contrato administrativo de servicios constituye una modalidad especial propia del Derecho Administrativo y es privada el Estado sujeta al régimen de la actividad pública. No se encontraba sujeto a la ley de Bases de la Carrera Administrativa, al régimen laboral de la actividad privada no a otras normas que regulan carreras administrativas especiales.

En esa línea, el CAS no era un contrato laboral sino un contrato Administrativo donde el particular no se comporta como un contratista ordinario, sino como un coadyuvante en la satisfacción de necesidades públicas por parte de la administración pública. El contratista no obstante que tenía un beneficio económico, obtenía dicho beneficios cumpliendo con la tarea de formar parte esencial del cumplimiento de cometidos públicos por parte del Estado.
Bajo este postulado, en el CAS no se podía aplicar las normas del Derecho Laboral, pues por definición y esencia no era un contrato de trabajo; no se generaba una relación laboral sino una relación contractual de prestación de servicios de naturaleza administrativa.

Sin embargo, esta situación jurídica fue aclarada por el Tribunal Constitucional en la STC EXP. N 0002-2010-AI, por la cual declara infundada la demanda de inconstitucionalidad contra la legislación del CAS, en la que ha establecido claramente que este contrato tiene características de un contrato de trabajo y no de un contrato administrativo, en la medida en que prevé aspectos tales como la determinación de la jornada de trabajo, así como los descansos semanales y anuales.

En consecuencia, más allá de la denominación dada a los contratos suscritos bajo el marco del Decreto Legislativo $\mathrm{N}^{\circ}$ 1057, estos contratos son de naturaleza laboral. Lo que fue reafirmado por el Tribunal Constitucional en la aclaración de la sentencia mencionada, señala que el contrato administrativo de servicios es un régimen laboral especial que respeta los derechos laborales individuales que reconoce la Constitución; y lo considera constitucional.

Huamán, O. (2012) sostiene que el régimen del contrato administrativo de servicios elimina, a decir del legislador extraordinario, como es el Poder Ejecutivo, el régimen de los servicios no personales. Es aprobado a través del Decreto Legislativo $\mathrm{N}^{\circ}$ 1057, que regula el régimen especial de contratación administrativa de servicios (CAS) más su reglamento cuya determinación consta en el Decreto Supremo $\mathrm{N}^{\circ}$ 075-2008-PCM, Decreto Supremo que aprueba el reglamento del Decreto Legislativo $\mathrm{N}^{\circ} 1057$ que regula el Régimen Especial de Contratación Administrativa de Servicios (RECAS) junto a los recientes cambios legislativos en el orden reglamentario fechadas a finales de julio 2011 con el Decreto Supremo $\mathrm{N}^{\circ}$ 065-2011-PCM Decreto que establece la modificaciones al Reglamento del Régimen de Contratación Administrativa de Servicios (M-RECAS), adicionando la ley N²9849, Ley que establece la eliminación progresiva del régimen especial de Decreto Legislativo $\mathrm{N}^{\circ} 1057$ y otorga derechos laborales (a partir de aquí: LEP-CAS) que recoge la gradualidad en el muerte del contrato laboral especial. 
Analysis of the administrative contract of services.

Desde nuestra perspectiva administrativista, el CAS recoge una raíz estatutaria sujeta al Derecho Administrativo, pero que en la realidad diaria de prestación de servicios a los entes públicos, configura un esquema de puntual laboralidad, esquema que pese a generar diversos beneficios al servidor público (horario de trabajo, seguro social, por citar los principales) en su aplicación juega contra derechos y principios fundamentales o constitucionales, al terminar afectando el derecho al trabajo y la primacía de la realidad; pero lo que es peor, a fundamentos básicos del Estado Constitucional y democrático de Derecho, tales como la irretroactividad de las normas y la irrenunciabilidad de los derechos laborales.

Los derechos individuales reconocidos al personal sujeto al contrato laboral especial de administración de servicios, según el tratamiento regulado en el M-RCAS $\left(\mathrm{N}^{\circ} 065\right.$ 2011-PCM) D.S y en la LEP-CAS (LEY N 29849) son los siguientes:

a. Percepción de remuneración no menor a la remuneración mínima legalmente establecida: derecho que descansaba desde sus inicios en el texto del reglamento en su $1^{\circ}$ DCF-Recas pero que la ley $n^{\circ} 29849$ ha considerado prudencial insertarlo en la regulación del artículo 6 de la norma general, Esto es el Decreto Legislativo $\mathrm{N}^{\circ} 1057$.

b. Jornada máxima de 8 horas diarias con un tope de 48 horas de prestación de servicios a la semana. Si el prestador de servicios labora en una entidad donde exista una jornada reducida establecida para los trabajadores sujetos a regímenes laborales generales, le debe ser aplicable dicha jornada laboral: esta previsión del artículo 6.1 del CAS repetida a excepción del acoplamiento al servidor administrativo al horario pro operario de la entidad empleadora en la LEP-CAS se desarrolla con extensión en el artículo 6 del RCAS, refiriéndose a la misma como jornada señalan máxima. Así el número de horas semanales de prestación de servicio según el reglamento no podrá exceder de un máximo de 48 horas de prestación de servicio por semana. Cabe en este apartado reiterar que la norma CAS (Dec. Leg. N ${ }^{\circ} 1075$ ) la del LEPCAS así como la del RCAS cumplen con el mandato del artículo $25^{\circ}$ de la Constitución, con lo que no obra conflicto, ni aparente ni real, entre la norma suprema y el D.L $\mathrm{N}^{\circ}$ 1057 , no entre este y el Decreto Supremo $N^{\circ}$ 075-2008-PCM, el RCAS y menos a con la Ley $\mathrm{N}^{\circ} 29849$.

c. Descanso de 24 horas continúas por semana como mínimo: Este es un derecho laboral que goza de ubicación constitucional, por lo expresado es también otro de los derechos del empleado público sujeto a la normativa del Estatuto CAS. Siendo un derecho laboral gravitante no puede pactarse un mínimo de horas que aquellas señaladas en la norma, bajo sanción de nulidad virtual, por la afectación al orden público, ya que al no estar contenido en una norma de carácter dispositivo, no integra el común acuerdo de la entidad y del personal de prestación de servicios para su goce, esto es la utilización del principio de la autonomía de la voluntad privada, al estar frente a una norma que ordena y no ante que permite disponer.

d. Uso de tiempo de refrigerio: Este es un derecho que no acogía en sus inicios el dictado original del artículo 6 de la norma general (D.L N ${ }^{\circ} 1057$ ) pero que la LEP-CAS asume llegando a recogerse actualmente como parte del catálogo de derechos del personal estatal sujeto al contrato especial de administración de servicios. En esta parte, no está demás recordar que este comprende el periodo de tiempo que la ley o en su defecto, la convención de las partes acuerdan en la relación prestacional de servicios para que el prestador de servicios, el trabajador, pueda tomar sus alimentos a fin de reparar prudencialmente sus fuerzas para la continuación de sus obligaciones asumidas en la relación bilateral empleadortrabajador sea en el sector público como entre los privados. En este punto "Se concede un tiempo prudencial y suficiente para el refrigerio de mediodía o la merienda intrajornarial, a fin de restaurar en parte el desgaste físico- mental del contingente laboral, debiendo ingerir los alimentos dentro del respectivo centro burocrático.

e. Percepción de aguinaldo por fiestas patrias y navidad conforme a los montos establecidos en las normas del presupuesto del sector público: Es este también un derecho incluido a razón de la LEP-CAS: curiosamente, pese a vocearse hasta el cansancio que la normativa del CAS no está sujeto a la LBCA 
ni a la LPCL, se viene usando un término empleado en el hábito estatutario como es el de los aguinaldos al otorgarse el derecho de mención a los trabajadores contratados o nombrados sujetos al régimen de carrera administrativa establecido en el decreto legislativo 276 además de los trabajadores sujetos al contrato administrativo laboral de servicios con el Estado lógicamente el goce de este derecho no será igual a una suma de acorde con la remuneración mínima vital, como sucede con los trabajadores del Estado sujetos a la LPECL sino antes bien a lo precisado, en la normativa presupuestal.

Hasta el año 2011, el derecho a gozar de aguinaldos no era posible de alegarse para el personal de CAS, en este punto, el Decreto Supremo $\mathrm{N}^{\circ}$ 219-aguinaldo por navidad en su artículo $12^{\circ}$, dejaba claramente establecido, en cuanto el personal del contrato administrativo laboral de servicio como al de locación de servicio, que la regulación de dicha norma no alcanza a dicho grupo de personal así como otros contratos de similar naturaleza; dicha situación, en la actualidad, ha cambiado enormemente en favor del personal sujeto al contrato especial laboral- administrativo de servicios con la precisión inserta en el artículo $6^{\circ}$ e) del CAS, modificado por la LEP-CAS regulación confirmada con la dación del Decreto Supremo N ${ }^{\circ} 106-2012-$ $\mathrm{EF}$, que dicta disposiciones reglamentarias para el otorgamiento del aguinaldo por fiestas patrias y aprueba una transferencia de partidas, norma publicada en el Diario Oficial El Peruano de 29 de enero de 2012.

f. Vacaciones de 30 días calendario (antes llamado "descanso continuo por año cumplido"). En la actualidad con la Ley $\mathrm{N}^{\circ} 29849$ se recibe el integro de la contraprestación, beneficio que comúnmente opera o se adquiere al año de prestación de servicios en la entidad.

g. Licencias con goce de haber por maternidad, paternidad y otras licencias a que tienen derecho los trabajadores de regímenes laborales generales: En cuanto a la licencia, debemos señalar de modo indiciario que es la autorización empresarial, sea a nivel del Sector Público como del Sector Privado, para inasistir al centro de trabajo de manera temporalmente breve, esto es, entre uno o más días; y que si bien se inicia a pedido del propio interesado, esto es, a pedido de parte, se encuentra condicionada a la conformidad de la institución empleadora, viéndose además formalizada, en el caso de entidades calificables como Administración Publica, a través de resolución o acto administrativo expreso.

En el caso de personal CAS, el catálogo de derechos modificados por LEP-CAS ha previsto el uso de licencias por maternidad, paternidad u otras, de las cuales podemos tratar a modo breve, ello a efectos de orientar al personal sujeto a este contrato especial:

g.1. El goce de la licencia por maternidad del personal CAS la referencia general o básica es a la Ley $\mathrm{N}^{\circ}$ 26644. Precisan el goce del derecho de descanso pre- natal y pos- natal de la trabajadora gestante (PGDPP) y al Decreto Supremo $\mathrm{N}^{\circ}$ 005-2011-TR que reglamenta la Ley $\mathrm{N}^{\circ} 26644$, que precisa el goce el descanso pre- natal y post-natal de la gestante.

g.2. El goce de la licencia por paternidad del personal CAS. Respecto del derecho a contar con la licencia por repetición en la paternidad, regulado en el artículo 8,a.2 de la M-RCAS como en su LEP-CAS, igualmente alcanza al personal sujeto al contrato laboral especial de administración de servicios. Este marco autoritativo de defensa de la unión familiar viene enlazado al mandato de la Ley $\mathrm{N}^{\circ}$ 29409, que concede el derecho de licencia por paternidad a los trabajadores de la actividad pública y privada(RLDLP), conjunto de normas que no hacen distingos en cuanto al régimen laboral o contractual al cual se adscribe el servidor civil; por lo tanto, sin que se incluya este derecho en la normativa reglamentaria CAS, el contratado en virtud de este nuevo régimen de empleo público gozaba ya del mismo.

g.3 el goce de la licencia por adopción. Habiendo llegado a establecer la LEPCAS que al personal de administración de servicios le resulta de aplicación otras licencias además de las de maternidad y paternidad, resulta posible que el personal CAS puede acogerse a la Ley No 27409 ley que otorga licencia laboral por adopción que en su artículo inicial, dedicado al objeto tiene derecho a una licencia con goce de haber correspondiente a 30 días naturales, 
contados a partir del día siguiente de expedida la resolución administrativa de colocación familiar y suscrita la respectiva Acta de Entrega del Niño, de conformidad con lo establecido por la Ley $\mathrm{N}^{\circ} 26981$ Ley de Procedimiento Administrativo de adopción de menores de edad declarados judicialmente en abandono (LPA-A) siempre que el niño a ser adoptado no tenga más de 12 años de edad, gozando de igual derecho el trabajador peticionario de adopción en situaciones reguladas en el artículo 128 a) y b) de la Ley $\mathrm{N}^{\circ}$ 27337, Código del Niño y Adolescente, siempre que el adoptado no tenga igualmente más de 12 años de edad.

g.4. El goce de otras licencias por parte del personal CAS: Además de las licencias antes señaladas, es posible que el personal sujeto al contrato laboral especial puede utilizar en su favor, las licencias aplicables a los regímenes laborales generales tales como:

- Las licencias por enfermedad, por fallecimiento del cónyuge, hijos o hermanos; por capacitación oficializada o institucional, por citación expresa en los ámbitos judicial, militar o policial así como por función edil, conjunto de licencias concedidas con goce remunerativos.

- Asimismo, las licencias sin goce de remuneraciones son igualmente aplicables al personal CAS, tales como las aplicables por motivos particulares o por capacitación no oficializada.

- Igualmente puede verse beneficiado por las licencias a cuenta del periodo vacacional, esto es, de las licencias por matrimonio, por enfermedad grave del cónyuge, padre e hijos, del mismo modo de uso por parte del personal al servicio del Estado sujeto a este contrato laboral- administrativo especial.

Como se puede apreciar, la ordenación de la LEP-CAS ha recogido derechos en cuanto a licencias que el prestador de servicios CAS tiene, ya que el hecho que el legislador nos los haya recogido en su momento, de ninguna manera puede llevarnos a pensar que el contratado laboral especial carecía de dichos derechos. En este aspecto, por lo menos, la Ley $\mathrm{N}^{\circ} 29489$ no aporta nada novedoso. h. Goce de los derechos regulados en la Ley $N^{\circ} 29783$, Ley de Seguridad y Salud en el Trabajo y en el Decreto Supremo N ${ }^{\circ} 005-$ 2012, reglamento de la Ley $\mathrm{N}^{\circ} 29783$, Ley de Seguridad y Salud en el Trabajo: Un tema de gravitante e insoslayable importancia de cara a la relación administrativo- laboralespecial de contratación de servicios es el relativo a la seguridad y salud del trabajador en la entidad pública empleadora. De primera mano es de precisarse que el objeto de la norma general, según la prescripción del artículo 1 de la LSST, es la de promover la cultura preventiva de riesgos laborales; para tal fin cuenta con el deber de prevención de los empleadores unido al rol fiscalización y control estadual y la participación de los trabajadores así como de sus organizaciones sindicales quienes, en sustento del dialogo social velan por promover, difundir y cumplir con dicha normativa.

A esto debe sumarse la precisión del artículo 2 de la ley que dedicado al ámbito de aplicación de la ley, establece que esta se expande a todos los sectores económicos y de servicio, comprendiendo a todos los empleadores y trabajadores bajo el régimen de la actividad privada en toda la nación al igual que a los trabajadores y funcionarios del Sector Publico, trabajadores de las Fuerzas Armadas y de la Policía Nacional del Perú, así como a trabajadores a cuenta propia. Si se toma en cuenta que los trabajadores incluyen a los del CAS que sufran algún accidente de trabajo o enfermedad profesional tiene derecho a las prestaciones de salud necesarias y suficientes hasta su recuperación y rehabilitación en procura de su reinserción laboral, caeremos en la cuenta que el principio de atención integral de la salud regulado en el artículo VI del texto preliminar de la norma, en la misma forma les resulta protector para este grueso número de personas al servicio de la administración pública. Del mismo modo el principio de protección con base en el artículo IX del título preliminar de la LSST, a través del cual se precisa el derecho de los trabajadores a que el Estado mismo y los empleadores aseguren condiciones de trabajo dignas que garanticen un estado de vida saludable, física, mental y socialmente en forma continua. 
i. Permiso por lactancia materna y su relación con los lactarios en el Sector Público. El personal sujeto al contrato administrativo de servicios, el cual ha sido incluido merced a la regulación de la Ley $\mathrm{N}^{\circ} 29849$, debiendo afirmarse, a modo de complemento, que el mismo encuentra puntual asentimiento en vía reglamentaria a través del artículo 8.a.1 de la M-RCAS. de lo señalado en mérito del artículo 8.a.1 del reglamento, se determina que la madre trabajadora- contratada CAS al término del periodo posnatal, tiene derecho a 1hora diaria de permiso de lactancia materna hasta que su hijo cumpla el año de edad, pudiendo realizarse el fraccionamiento de dicho permiso en dos tiempos iguales y otorgados dentro de su jornada de trabajo sin descuento alguno; esto en mérito a lo ordenado en la Ley $\mathrm{N}^{\circ} 27240$, que otorga permiso por lactancia materna (LOPLM) unido a la Ley $\mathrm{N}^{\circ} 27591$ que equipara la duración del permiso por lactancia de la madre trabajadora del régimen privado con el público; y a la Ley $\mathrm{N}^{\circ} 28731$, que amplía la duración del permiso por lactancia materna.

j. Afiliación al régimen contributivo que administra el Seguro Social de Salud (EsSalud). El tema de la seguridad social es otro punto que para el personal de empleo público por servicio no personal se ha descuidado desde un inicio, pese a ser un derecho de raigambre constitucional, precisión que busca corregir la normativa del CAS antes de la Ley $\mathrm{N}^{\circ} 29849$, prescribe que a estos efectos, la contribución -que ha de ser pagada a partir del 01 de enero del 2009 en mérito a la 3 DCF del reglamentotiene como base máxima el equivalente al $30 \%$ de la UIT vigente en el ejercicio por cada asegurado- en este año ascendente el citado $30 \%$ a la suma de S/ 1,050.00 nuevos soles- ,artículo que viene desarrollado en el artículo $9^{\circ}$ del RCAS. Conforme al artículo 9,1 del reglamento, las personas que prestan servicio bajo la modalidad del Régimen Contributivo de la Seguridad Social en Salud (RCSSS) de acuerdo con el artículo 3 de la Ley de Modernización de la Seguridad Social en Salud, la Ley Nº 26790 y sus demás normas reglamentarias y modificatorias, estando comprendidos los derechohabientes a los que se refiere la Ley de Modernización de la Seguridad Social en Salud. k. La afiliación a un régimen de pensiones, pudiendo elegir entre el Sistema Nacional de Pensiones (SNP) o el Sistema Privado de Pensiones (SPP) y cuando corresponda, afiliarse al Seguro Complementario de Trabajo de Riesgo (SCTR). En cuanto al tema de los derechos reconocidos al antes llamado personal por servicios "no personales", el CAS como norma de contenido cerrado ha recogido el derecho del servidor contratado a gozar del sistema pensionario como lo ordena la Constitución, lo cual es un avance en el reconocimiento de la condición de empleados públicos de este importante bloque de prestadores de servicios a la administración sujetos a dependencia con respecto de su contratante.

\section{EL DERECHO LABORAL}

\section{Concepto y finalidad}

El concepto de derecho del trabajo tiene que ver con el ámbito de aplicación de dicho sistema normativo. En efecto, la acepción que se utiliza para el término trabajo no es la común, destinada a referirse a cualquier ocupación del hombre. Es una acepción cualificada, pues demanda específicas características, las cuales le dotarán de protección jurídica.

Dichas características son la prestación personal del trabajo mismo, la subordinación y la remuneración. La reunión de estas tres características hace una relación laboral. Si faltase uno de ellos, no se llegaría a configurar la relación laboral. Por cierto, que pueden existir otros factores, pero no son fundamentales para constituir una relación laboral, sino acaso un régimen laboral o ciertos beneficios, como podría ser la estabilidad laboral, la compensación por tiempo de servicios, entre otros.

El trabajo como actividad deliberada del ser humano dirigida a una finalidad determinada debe ser protegido por el derecho del trabajo, excepto claro está cuando dicho objetivo sea ilícito.

La primera de las tres condiciones para que el trabajo sea protegido por el derecho laboral, es la prestación personal de la actividad humana, lo que implica que el trabajador sea necesariamente una persona natural, que la acción la ejecute personalísimamente. En 
el CAS, se da sin lugar a dudas este primer requisito, pues el Estado como empleador contrata bajo dicho régimen a una persona natural para desempeñar funciones públicas.

El segundo requisito es la subordinación, que viene a ser un vínculo jurídico entre el empleado y el empleador. En virtud de este ligamen, el empleado queda sujeto a la realización de la actividad y el empleador a organizar, dirigir, fiscalizar y sancionar, según el caso, dicha actividad. En el CAS también se verifica este requisito, pues el trabajador contratado bajo este régimen acata la dirección y el control del empleador.

El tercer requisito es la remuneración, que es la contra prestación del contrato a cargo del empleador, por el trabajo realizado por el trabajador, lo cual también se da en el régimen CAS.

De lo anterior desciende inconcusamente que el régimen CAS es un contrato laboral con todas las notas características de éste, que son las mismas que se dan en los otros regímenes laborales, público y privado, del Estado, por lo que le corresponde al trabajador CAS los mismos derechos laborales reconocidos constitucionalmente para aquello.

No es posible considerar al CAS como un contrato de trabajo atípico, pues como sostiene Neves, J. (2009), los elementos típicos de todo contrato de trabajo son la duración de la relación laboral, esto es, la duración indefinida; la duración de la jornada de trabajo; el número de empleos; y el lugar de trabajo.

En tal caso, cuando un contrato laboral es de duración temporal, no está exento del goce de todos los derechos laborales, tal como sucede con los contratos previstos en el régimen laboral de la actividad privada. Este carácter de temporalidad no es suficiente para justificar la negación de derechos laborales. La cuestión aquí es que la propia norma jurídica del CAS ha excluido irrazonablemente a los trabajadores de los derechos laborales, debido a motivaciones económicas. Es inimaginable el ahorro estatal por las compensaciones por tiempo de servicios de los trabajadores CAS, por ejemplo.

Ligado al concepto de derecho del trabajo también está el concepto de fuentes del mismo. La suprema fuente es la Constitución, cuya naturaleza es social en este punto, al punto que figura como un deber y un derecho, como medio de realización personal y como objeto de protección por el Estado, de acuerdo a lo cual deben regularse e interpretarse los derechos laborales, por lo que no cabe duda que el trabajador CAS está amparado por la Constitución y en consecuencia le corresponde gozar de todos los derechos laborales de los otros trabajadores públicos.

\section{Principios juridicos laborales}

\section{Principio de continuidad}

La ausencia de este principio en el contrato administrativo de servicios, causa inseguridad en la relación laboral, ya que en el artículo $5^{\circ}$ del Reglamento del Decreto Legislativo $\mathrm{N}^{\circ} 1057$ se indica que es de plazo determinado y que la duración del contrato no puede ser mayor al periodo que corresponde al año fiscal; ahora bien lo que se busca con el principio de continuidad es la duración del contrato de trabajo, toda vez que se presume la continuidad en la prestación del servicio teniendo como sustento la regla general "contrato de trabajo a plazo indeterminado".

Por lo tanto, lo que se busca es evitar la interrupción arbitraria, incausada de la relación laboral y, por ende, la sustitución sin mayor protección que solo la indemnización de tres remuneraciones como máximo, según el último párrafo del artículo 10 de la Ley $\mathrm{N}^{\circ}$ 29849, que establece la eliminación progresiva del Régimen Especial del Decreto Legislativo $\mathrm{N}^{\circ} 1057$ y otorga derechos laborales; sin duda esta protección reparadora que contiene el CAS no es igual al contrato del Régimen de la Actividad Privada del Decreto Legislativo $\mathrm{N}^{\circ}$ 728 , que concede una remuneración y media ordinaria mensual por cada año completo de servicios, en un máximo de 12 remuneraciones, según lo establecido en los artículos 34 y $38^{\circ}$ de la Ley de Competitividad y Productividad Laboral.

Asimismo, el Tribunal Constitucional ampara el derecho de permanencia, continuidad y estabilidad a los trabajadores del régimen del Dec. Leg. N728 a quienes le reconocen la protección contra el despido arbitrario en la vía amparo, dejándolo al arbitrio a este si cobra la indemnización o reclama la reposición laboral, evidenciándose que está protegido más allá de lo previsto por la ley de las exigencias de los 
tratados internacionales como la Declaración Universal de los Derechos Humanos; Protocolo adicional a la Convención Americana sobre Derechos Humanos en materia de derechos económicos, sociales y culturales.

\section{Principio de primacia de la realidad}

Se refiere a que en caso exista discordancia entre lo que ocurre en la práctica y lo que surge de los documentos o acuerdos suscritos entre el trabajador y empleador se tomará en cuenta lo primero; es decir prevalece los hechos, este principio se encuentra protegido en el artículo $22^{\circ}$ de la Constitución Política del Perú, norma que prescribe la limitación del ejercicio de los derechos constitucionales y laborales, así como al carácter de irrenunciabilidad de derechos laborales amparado en el artículo $26^{\circ}$ del citada Carta Magna.

Ahorabien, el TribunalConstitucionalhadefinido que el CAS es un régimen especial regulado por su propia norma especial y confirmando sus propios beneficios y obligaciones propias de su régimen especial; empero el CAS tiene los mismos elementos esenciales del contrato de trabajo, ¿porque entonces la diferencia de los otros regímenes laborales de la actividad privada y del Decreto Legislativo 276? ¿Sí la prestación de servicio es el mismo? ¿No debería tener todos los derechos laborales reconocidos por la Constitución? El Tribunal Constitucional cae en una evidente contradicción porque en reiteradas jurisprudencias solo para mencionar una de ellas STC No 1944-2002-A.TC, ha hecho uso del principio de primacía de la realidad, de la misma manera la Organización Internacional del Trabajo en la recomendación 198. Sobre la relación de trabajo adopta en Ginebra 95 $5^{\circ}(15 / 06 / 2006)$ Art. 9० “(...) la existencia de una relación de trabajo debería determinarse principalmente de acuerdo con los hechos relativos a la ejecución del trabajo y la remuneración del trabajador, sin perjuicio de la manera en que se caracterice la relación en cualquier arreglo contrario ya sea de carácter contractual de otra naturaleza convenida por las partes.

\section{Principio de irrenunciabilidad de los derechos laborales:}

Es la imposibilidad jurídica que tiene un trabajador en que se prive voluntariamente de una o más ventajas concedidas por el derecho en beneficio propio, es decir, los derechos reconocidos por los trabajadores son irrenunciables, dicho principio está protegido en el artículo $26^{\circ}$ de la Constitución Política "el carácter irrenunciable de los derechos reconocidos por la Constitución y la ley" y todo pacto en contrario a este principio es también nulo.

Al respecto el trabajador CAS solo podrá disponer de los derechos laborales que le brinda el Decreto Legislativo 1057, pero que sucede con los derechos laborales que no se encuentran disponibles para los trabajadores CAS, pero claro si están contemplados para los trabajadores de la actividad privada como por ejemplo: compensación por tiempo de servicios, asignación familiar, gratificación julio $\mathrm{y}$ diciembre, bono de escolaridad, estabilidad laboral, protección contra el despido arbitrario gozando del derecho a la indemnización o a la reposición respectiva; eso significa que el Estado como empleador excluye esos derechos reconocidos e irrenunciables que por principio de primacía de la realidad se le reconozca aquellos que la Administración (Estado) ha omitido en reconocer de hecho o de derecho en esta relación jurídica a los trabajadores CAS.

\section{Principio de igualdad de oportunidades sin discriminación}

Este principio se encuentra regulado en el inciso 1 artículo $26^{\circ}$ de la Constitución Política; y constituye una manifestación del derecho a la igualdad en el ámbito laboral- igualdad de trato- esto es que el Estado o los particulares, en relación a las actividades laborales, no genere una diferenciación no razonable y por ende arbitraria. Sin embargo en el CAS existe una evidente desigualdad en el ejercicio de los derechos fundamentales, pretendiendo el Tribunal Constitucional justificar "objetivamente y razonablemente" que el CAS es un régimen especial y como tal tiene sus propios derechos laborales, vulnerando el derecho a la igualdad entre los regímenes laborales existentes que sí ostenta el empleado público sujeto al Ley de Productividad y Competitividad Laboral, norma en la cual el Estado contrata a su personal.

Por otro lado, el trato desigual que incurre el Estado como único empleador por los distintos regímenes laborales genera desigualdad, discriminación y arbitrariedad; en la prestación de servicios resultan ser permanentes: unos 
gozan con estabilidad laboral absoluta, otros con tutela indemnizatoria regulado en la Ley de Productividad y Competitividad Laboral ello en el artículo $34^{\circ} \mathrm{y}$ otros en el mejor de los casos tutela resarcitoria y la tutela indemnizatoria a escoger del demandante.

Sin embargo en el Contrato Administrativo de Servicio la tutela ante el despido incausado es incierta ya que en la norma sostiene que el contratado CAS ante la resolución de su contrato al estar privado de su empleo podrá tener " la penalidad" o indemnización especial pagada inicialmente por dos contraprestaciones, el mismo ha sido enfatizado por el Tribunal Constitucional en la STC $\mathrm{N}^{\circ}$ 03818-2009-PATC y luego aumentado por el pago de 3 remuneraciones dejados de percibir conforme al artículo $10^{\circ}$ del Reglamento del CAS y la Ley $\mathrm{N}^{\circ}$ 29849; entonces, cómo queda la primacía de los derechos fundamentales en especial con el cuidado al trabajador contra los actos materiales o formales de terminación unilateral del empleo público, dónde queda el derecho al trabajo a no ser despedido salvo por causa justa; la posición de la suscrita es que sin duda es inconstitucional el pago de la penalidad o indemnización especial a los trabajadores CAS por ir contra la adecuada protección contra el despido arbitrario; enervándose de esta manera la igualdad de trato.

\section{Los derechos laborales}

Los derechos constitucionales laborales que tiene el trabajador son, en primer lugar, una remuneración equitativa y suficiente, que procure para él y su familia el bienestar material y espiritual; por lo que el pago de la remuneración y de los beneficios sociales goza de un privilegio sobre cualquier otra obligación del empleador.

Luego, la jornada máxima ( 8 horas diarias o 48 horas semanales), los descansos remunerados (semanales y anuales), los derechos colectivos (libertad sindical propiamente dicha, negociación colectiva y huelga), la protección contra el despido arbitrario y la participación anual en las utilidades.

Evidentemente, para la protección de estos derechos que tiene el trabajador, se le debe brindar igualdad de oportunidades sin discriminación; carácter irrenunciable de dichos reconocidos por la Constitución y la ley; y en caso de duda insalvable sobre el sentido de una norma, la interpretación en el sentido más favorable al trabajador.

Respecto a la remuneración ya se ha hecho referencia a su importancia como derecho al tratar los requisitos para que exista un contrato de trabajo. Solo cabe agregar que es la contra prestación que espera el trabajador por parte del empleador por su actividad consciente y energía personal en que constituye su trabajo, a través del cual se realiza, desarrolla y trasciende como ser humano.

La compensación por tiempo de servicios es un derecho-beneficio del trabajador de previsión social ante las contingencias que causa el cese en el trabajo. Por ello, no hay razón para que no se otorgue al trabajador CAS. La temporalidad del contrato en este caso no es óbice para negar este derecho, ya que el trabajador tiene derecho a la compensación por tiempo de servicios después de haber cumplido un mes de prestación de servicios subordinados mayor a cuatro horas diarias, según el Texto Único Ordenado del Decreto Legislativo $\mathrm{N}^{\circ} 650$, modificatorias y complementarias.

Las gratificaciones ordinarias es otro derecho laboral que inicialmente fue conculcado a los trabajadores CAS. Estas son remuneraciones otorgadas por el empleador por mandato de ley con ocasión de Fiestas Patrias y Navidad. Los trabajadores con contrato a plazo fijo tienen derecho a ellas, por lo que no era razonable negar este derecho a los trabajadores CAS.

El trabajo en sobretiempo o jornada extra ordinaria, siempre que ocasione utilidad al empleador; esté relacionada con las actividades habituales del trabajador y haya sido registrado; es un derecho laboral. Sin embargo, pese al carácter laboral del contrato CAS, este derecho no se le reconoce al trabajador público sujeto a este régimen.

La asignación familiar es otro de los derechos laborales no reconocidos al trabajador CAS, no obstante tener carácter y naturaleza remunerativa; y ser percibida por los trabajadores públicos sujetos al régimen de la actividad privada.

Otros derechos laborales como los descansos remunerados, descanso pre natal y post natal, entre otros, ya gozan los trabajadores CAS, por lo que no se desarrollan en este acápite. 


\section{LA DIGNIDAD HUMANA Y LOS VALORES DEMOCRÁTICOS}

\section{La dignidad humana}

La imagen, significación y noción del hombre que existe en un espacio y tiempo histórico es un requisito indispensable del orden jurídico vigente en dicho tiempo y lugar. Por ello, no resulta comprensible una regla de derecho que no se corresponde con dicha consideración.

Es la dignidad humana, de la que derivan los derechos humanos, naturales, esenciales y fundamentales, la que sirve de referente para deducir esa imagen y significación del hombre que consagra la Constitución Política de todo Estado. En nuestro país, el artículo 1 de la Ley Fundamental tiene inequívocamente una raíz antropocéntrica que debe dotar a todo el orden jurídico y político de una impronta axiológica que evite la afectación de la persona humana.

En buena cuenta, la imagen que la Constitución tenga del hombre es un elemento sine qua non para interpretar y comprender el orden jurídico y político. En esa línea, cada derecho humano proviene de esa imagen constitucionalmente consagrada, que configura la dignidad humana, la cual a decir de Gutiérrez, I. (2005) es el núcleo irreformable de la Constitución. Y el artículo $1^{\circ}$ de nuestra Carta Política (Congreso de la República, 2013) consagra que "la defensa de la persona humana y el respeto de su dignidad es el fin supremo de la sociedad y el Estado", por lo que es de deducir que nuestra Constitución Política tiene una imagen preponderante del hombre que debería informar el orden político y jurídico.

Esta posición es desarrollada por Smend, R. (1985), según el cual, la dignidad humana se concibe conforme a ciertos presupuestos del ius naturalismo racionalista, que es la ontología de los derechos naturales que permite el estudio de la sociedad y de sus construcciones morales, políticas y jurídicas, al extremo que el mayor aporte de esta filosofía político jurídica no es solo el concepto de derecho natural sino el conocimiento de la sociedad como ciencia de lo moral. Por esta razón, la dignidad humana es un principio del cual dimanan los derechos fundamentales, como sistema de valores concreto, entre los cuales se encuentran primordialmente la libertad y la igualdad, que configuran precisamente un estado democrático y de derecho.
Es, justamente, un sistema de plena salvaguarda de la libertad y la igualdad, lo que hace que el legislador en un estado democrático esté en una posición de inferioridad respecto a la jurisdicción constitucional, que es la encargada de la interpretación del sistema de valores. Sin embargo, tal parece que este sistema de valores en cuya cúspide nuestra Constitución Política ha ubicado al ser humano, no ha servido para que el CAS sea declarado inconstitucional por la jurisdicción constitucional.

En ese sistema axiológico, la afirmación constitucional de la dignidad humana, avala las posibilidades de progreso de cada individuo $y$, de esa manera, la diversidad efectiva de los hombres en función del ejercicio legítimo de las libertades. La dignidad, así, se mantiene enhiesta como principio ius naturalista generador de derechos esenciales de la persona humana, frente a la regla jurídica.

Ahora bien, el alcance de la dignidad humana llega hasta el punto de impedir que la persona humana sea convertida en objeto de una regla de regulación normativa o de una decisión extraña. No debe ser objeto de la actividad del poder público ni un medio para fines de la comunidad. El ser humano no es un instrumento, es sujeto y destinatario del respeto de la sociedad y del estado. Sin embargo, vemos como la regulación normativa del CAS convierte al trabajador en un medio y un objeto de decisiones extrañas.

No obstante, el carácter inmaterial de la dignidad humana, sostenido por la doctrina y el texto constitucional, requiere sortear efectivamente el riesgo de recurrir a ella de manera fundamentalista para resolver situaciones complejas de índole estatal y social. En opinión de la investigadora, la dignidad humana se ve en todo caso afectada en todas aquellas situaciones en las que la existencia del hombre se tropieza con el desamparo, la necesidad, la amenaza, la inseguridad y la degradación, como ocurre en el caso del CAS, puesto que es obvia la necesidad de trabajo y, sin embargo, el Estado como empleador nutre de inseguridad al ser humano por la renovación mensual de los contratos; la jurisdicción constitucional no presta tutela efectiva sumiéndolo en el desamparo en caso de no renovación; y la afectación de la dignidad humana degrada a la persona al no reconocer determinados derechos laborales, frustrando con ello su desarrollo personal a través del trabajo para el Estado. 
Analysis of the administrative contract of services.

La razón que sostiene precisamente este concepto y alcance de la dignidad humana, es su consideración como principio, del cual emergen todos los derechos fundamentales; y no como un derecho humano específico, pues como tal tendría que ser limitado por definición. Es, pues, necesario invocar la dignidad humana, más allá de los derechos humanos que la concretan. No es concebible la instrumentalización de la dignidad ni de los derechos humanos para lograr otros fines, pues éstos devendrían en espurios, ya que el hombre violado en su dignidad deviene en objeto y la pérdida de su calidad de sujeto, como mero medio para conseguir otros fines o como una cosa susceptible de ser cambiada por algo, es una degradación. Parafraseando a Kant se podría afirmar que la persona humana, tal como la consagra el artículo primero de nuestra Constitución aparece como la expresión más acabada de un mandato de deber ser o, como dice Álvarez, N. (1999, página 36) "la dignidad humana es un presupuesto lógico del deber".

Ahora bien, pese a la excepcionalidad teórica y dogmática de la dignidad humana, su aplicación deja mucha insatisfacción, constituyendo un verdadero desafío en dar a este principio jurídico constitucional de un control riguroso para evitar trasgresiones y, más bien, dotarlo de real fuerza vinculante para fomentar su reproducción racional. En otras palabras, hacer operativa la dignidad humana delimitando su alcance claramente, a fin de evitar también su invocación especuladora.

\section{Los valores democráticos}

Los valores democráticos son las ideas y creencias que encaminan a la sociedad a actuar de determinada forma, con sujeción a los principios de libertad, igualdad y justicia, de tal forma que permiten ejercer plenamente la democracia, para vivir en paz y en armonía.

El estado como organización jurídico política está compuesto por la población, el territorio y el poder. Las funciones de éste son ejercidas por el gobierno. De tal manera que hay formas de estado y formas de gobierno, según sean las formas de organización de cada uno.

Si nos preguntamos ¿quién manda? estamos inquiriendo por ¿quiénes son los gobernantes? Entonces la respuesta estará referida a la estructura funcional y relacional de los distintos órganos del poder.
Por el contrario, cuando nos preguntamos ¿cómo manda? Estamos inquiriendo por el modo cómo se ejerce el poder, que es un asunto esencial y conmueve el ser del estado mismo.

Para saber cuándo un estado es democrático, tenemos que vincular el poder con los otros elementos del estado. Cuando lo relacionamos con el territorio, el estado puede ser unitario o federal, según sea que el poder sea ejercido políticamente centralizado o descentralizado; y cuando relacionamos el poder con la población, el estado puede ser democrático, autoritario o totalitario, según se respete su dignidad y derechos fundamentales; se restrinja; o se desconozca.

Detrás de cada forma de estado, hay una cosmovisión ideo política en la visión que se tiene de la imagen del hombre y del régimen político en que se lleva a cabo la convivencia humana. En la forma de estado totalitaria, existe una razón suprema que no es el respeto a la dignidad del hombre, sino el propio estado, que se convierte en un fin en sí mismo. Es lo que se conoce como la razón de estado. Existe para su propio bien y grandeza.

Hay aquí, según Bidart, G. (2002), un monismo sociológico, pues la realidad primaria es el colectivo social, es el hombre para la sociedad y el estado, vale solo en cuanto es miembro de la sociedad. Esta ideología deja al hombre sin vida propia y postula que su existencia personal solo tiene sentido en medio de lo social, que puede ser la etnia, una clase social, la nación, entre otras, por lo que encierra el peligro de desconocer al hombre que pertenezca a otros medios sociales.

También existe un monismo político porque coloca al poder político como el único poder social que absorbe a los otros, a los que niega en tanto sean independientes o adversos.

Es, asimismo, un monismo jurídico por cuanto concibe que el jus naturalismo no existe; y que solo existe el positivismo jurídico que el estado crea con las reglas de derecho.

Como es fácil advertir, el estado totalitario busca fines fuera de la persona, con los que pretende satisfacer supuestos valores que la misma encarna. 
Evidentemente, el estado democrático velará por la defensa y el respeto de la dignidad y los derechos y libertades fundamentales de la persona humana, a la que reconoce como un fin per se. Toda su organización estará encaminada a constituirse como un medio idóneo para lograr el desarrollo humano de sus miembros.

No obstante lo anterior, la democracia también es presentada como una forma de gobierno, consistente en la convicción de que el pueblo se debe gobernar a sí mismo por ser el titular de la soberanía y el poder, ya sea directamente o por medio de una representación política, la de los gobernantes, que es una ficción política, pues se supone que los que ellos hacen lo ha hecho el pueblo. Este es el quid del asunto, la representatividad del gobierno que le dota de legitimidad, en la medida que cumplan los representantes con gobernar de acuerdo al mandato del pueblo y no en función de intereses de grupos o del mismo estado, desconociendo la dignidad y los derechos fundamentales de la persona.

En cualquiera de las formas democráticas de estado y de gobierno, el indispensable que el poder en su relación con la población sea ejercido con respeto a la persona humana, para posibilitar la convivencia humana en justicia, paz y libertad.

La democracia es, al mismo tiempo, un sistema político y una manera de comprender las relaciones sociales. Es un plebiscito diario y un talante de convivencia entre los hombres que se guardan respeto y consideración, reconociéndose con dignidad, derechos $\mathrm{y}$ deberes iguales.

Esta forma de concebir la democracia conlleva asumir un conjunto de valores éticos para su práctica y fomento en todos los órdenes de la vida, los cuales están asentados en los principios de dignidad, igualdad y libertad, que actuarán como vectores conducentes a la seguridad, la paz, la autolimitación, la colaboración, la participación, la pluralidad, la diversidad y la tolerancia entre todos sus miembros.

Los valores democráticos son significativos porque involucran razonamientos previos que inspiran a las personas para actuar en sociedad respetando a los demás y a las autoridades a regirse por el jus naturalismo para respetar la dignidad y los derechos fundamentales en busca de la justicia, frente a una regla jurídica que desconoce los derechos laborales a un grupo significativo de trabajadores del estado.

\section{La naturaleza del derecho}

Las tesis más conocidas sobre la naturaleza del derecho son el jus naturalismo, el positivismo, la teoría tridimensional y la dual.

El iusnaturalismo sostiene que existe un Derecho Natural que es superior al Derecho Positivo creado por los hombres mediante normas jurídicas y que está compuesto por un conjunto de valores que inspira su contenido y guía la actuación y decisiones de los operadores del Derecho; no pone a prueba racionalmente las convicciones éticas y valorativas y permite descubrir semejanza y equilibrio donde hay divergencia y discordancia. Al respecto, el artículo II de la Declaración de los Derechos y Deberes del Hombre y del Ciudadano de Francia de 1789 estableció que: "La finalidad de todas las asociaciones políticas es la protección de los derechos naturales e imprescriptibles del hombre; y esos derechos son libertad, propiedad, seguridad y resistencia a la opresión", lo cual pone de manifiesto que la norma jurídica no estatuye derechos, simplemente los reconoce y declara, por ser anteriores a ella. Eventualmente los desconoce o rebaja y es entonces cuando se produce el conflicto.

El positivismo postula la separación de todo aquello que pertenece a otras ciencias, tales como los valores y las conductas, que son elementos propios de la moral, la religión, la sociología o la política, que viene a ser una especie de purismo jurídico, en el que la norma jurídica válida hace un el sistema eficaz que regula efectivamente las conductas de los sujetos y la sociedad en su conjunto. La visión del Derecho que tiene esta teoría es la de una pirámide en cuya cima está la norma que lo sostiene, que no es un texto legislativo sino una hipótesis sobre su eficacia, que viene dada por el cumplimiento de todos los miembros de la sociedad, lo que crea el orden jurídico, así la Constitución es la primera norma esencial porque establece las reglas acerca de quién gobierna y cómo lo hace; y como se elaboran las normas inferiores, cuya validez depende que se conformen con el mandato superior en fondo $\mathrm{y}$ forma. 
Conforme al pensamiento de Hans Kelsen, el positivismo es un orden normativo o sistema de normas que se propone provocar una conducta determinada mediante la prevención de que en caso que se produzca una acción contraria, la consecuencia será un acto coactivo o sanción. Ernst Fornsthoff, citado por Kelsen, afirma que el positivismo reconoce que el Estado dispone del Derecho, lo que nos remite a la idea de la soberanía.

De esta manera, la consecuencia natural del positivismo es la separación que hace del derecho y la moral, incluido el derecho natural, porque no es constituido por actos de voluntad humana, sino que es deducible de la naturaleza. Recuérdese al efecto que se denomina positivismo porque toma como objeto de la ciencia únicamente lo dado, lo comprensible, lo positivo, no lo metafísico trascendente, lo supra sensible, los conceptos derivados de causas primeras y formas apriorísticas del pensamiento.

No obstante, el propio Kelsen se encarga de advertir que esta separación entre derecho positivo y derecho natural no significa la negación de un derecho justo y de armonía con la moral, pero observa que existen distintos sistemas de moral y de justicia; que un orden normativo puede satisfacer un sistema de justicia y de moral pero no otro; y que la validez del derecho positivo es independiente de la moral y de la justicia.

La teoría tridimensional sostiene que el Derecho tiene componentes esenciales e inescindibles, que son la conducta, la norma y los valores. El derecho en el plano lógico es una ligazón bilateral de Ia conducta humana para Ia realización ordenada de los valores de convivencia. Empero, como deber ser es una exigencia de realización de valores, que tienen éstos la característica de presentarse como fines, de ahí que la justica sea el fin último del derecho y la paz social el de la política, en ambos casos resolviendo los conflictos inter subjetivos de intereses que se presentan entre los hombres.

La teoría dual, por su parte, no es compatible con el positivismo porque éste excluye la eventualidad de introducir explicaciones morales al derecho, porque son elementos no autoritativos y el derecho sólo comprende elementos autoritativos; asimismo porque supondría que sería posible que el derecho tuviese una extensión crítica vinculada con la corrección.
Es, en cambio, compatible con el jus naturalismo no extremo, porque en éste los elementos morales son indispensables para responder fundadamente a problemas jurídicos $\mathrm{y}$ es conveniente introducirlos necesariamente al derecho. Sin embargo, versiones extremas de esta teoría afirman que los defectos morales traen como consecuencia la pérdida de validez jurídica.

Ahora bien, la coerción es indispensable para que el derecho cumpla las funciones que le imponen los valores con los que el derecho tiene una unión forzosa, como son, la certeza y la eficacia jurídica. De otro lado, la propiedad fundamental del derecho que caracteriza a la corrección como una propiedad esencial del mismo, es que la injusticia extrema no es derecho, debido precisamente a la pretensión de corrección del Derecho.

Como se puede apreciar, para esta teoría el Derecho tiene una dimensión ideal o crítica y una dimensión real o fáctica, las cuales se compenetran pues la finalidad del Derecho es componer los conflictos en justicia, por lo que es un producto cultural histórico.

\section{El principio jurídico y la regla de derecho}

El Derecho integra patrones de comportamiento como las normas y las definiciones. Las normas pueden ser reglas o principios.

La noción de principio refiere a una norma programática o directriz que fija la obligación de lograr determinados fines; que expresa los valores supremos de un ordenamiento jurídico y que son el reflejo de una determinada forma de vida; que es de elevada jerarquía, de ahí que todos se encuentren en la Constitución Política y en los códigos jurídicos; que enuncia una máxima de la ciencia jurídica de un considerable grado de generalidad y que orienta la sistematización del ordenamiento jurídico o de un sector del mismo. El principio jurídico puede o no estar incorporado al Derecho positivo.

¿Cómo se pueden diferenciar los principios de las reglas? Estructuralmente las normas pueden ser vistas como entidades organizadas de una cierta forma, como conjuntos de propiedades y soluciones. Funcionalmente las normas 
pueden ser consideradas de acuerdo con el rol que cumplen en el razonamiento práctico de sus destinatarios. Es decir, como razones para la acción.

Los principios se formulan como enunciados que armonizan casos con soluciones, en forma abierta e indeterminada, mientras que las reglas lo hacen de forma cerrada. Alexy, R. (1988) sostiene al respecto que el punto decisivo para la distinción entre reglas y principios es que los principios son normas que ordenan que se realice algo en la mayor medida posible, son por consiguiente mandatos de optimización que se caracterizan porque pueden ser cumplidos en diversos grados. En cambio, las reglas son normas que exigen un cumplimiento pleno $\mathrm{y}$, en esta medida, pueden siempre ser sólo cumplidas o incumplidas.

Los principios cumplen con una función explicativa por su capacidad para sintetizar y sistematizar una gran cantidad de información y cumplen, por tanto, una función didáctica de una gran importancia; y también nos permiten entender el Derecho no como un simple conjunto de pautas, sino como un conjunto ordenado, esto es, como un conjunto dotado de sentido. Por ello, conocer los principios del Derecho permite predecir cuáles son las soluciones a los problemas jurídicos fijadas en disposiciones específicas al proporcionar criterios para la aplicación, interpretación y modificación del Derecho.

Los principios son, a nuestro juicio, más que las reglas, porque al estar enunciados genéricamente, permiten un mayor número de situaciones, esto es, al tener un mayor poder explicativo que las reglas, tienen también un mayor alcance justificatorio.

Vistos así los principios y las reglas jurídicas, el Derecho constituye un sistema excluyente, por cuanto impone el deber de formar un balance de razones integrado únicamente por las razones constituidas por los principios jurídicos, siendo admisible considerar otras razones únicamente en la medida en que los propios principios jurídicos lo permitan; y además porque tal balance de razones remite a adoptar como base de la resolución del conflicto una regla jurídica justa, esto es, una razón perentoria adecuada.

\section{El principio jurídico y la necesidad dela prevalencia del principio jurídico sobre la regla normativa}

El positivismo jurídico sostiene que los únicos derechos existentes son los derechos reconocidos por el ordenamiento jurídico. Para Durkheim, R. (1989) existen derechos legales pero también derechos morales. Ambos coexisten en un mismo sistema jurídico y aquellos no prevalecen necesariamente sobre éstos. La razón es que la finalidad del sistema jurídico es garantizar los derechos individuales frente a las afectaciones y violaciones por parte del gobierno y de la mayoría.

Aplicar las reglas jurídicas sin sustentarlas en otras pautas estandarizadas que no son reglas sino principios, significa escatimar el importante rol que cumplen éstos en el logro de la finalidad del Derecho, que es alcanzar la justicia para contribuir a la construcción de la paz social.

Durkheim, R. (1989) afirma que el principio jurídico es un patrón que ha de ser cumplido no porque favorezca una situación económica, política o social que se considera anhelada, sino porque es una exigencia de la justicia, la equidad o la moral.

La regla jurídica es aplicable a manera de disyuntivas, de donde se sigue que si los hechos están subsumidos en ella, entonces si la regla es válida tendrá que ser acatada, y si no es válida, entonces no se toma en cuenta. El principio tiene una importancia y un peso específico en el sistema, como orientador e inspirador de decisiones de las autoridades.

En efecto, la discrecionalidad para, por ejemplo, interpretar la Constitución Política en el extremo de los derechos laborales, para justificar que no se les otorga a los trabajadores del Estado sujetos al régimen CAS, no es un ejercicio de libertad ilimitada ni exenta de crítica.

Por el contrario, está sometida a determinados patrones de justicia, racionalidad y eficacia. Pero en la discusión de si los principios jurídicos son o no obligatorios; y si pueden determinar un resultado en particular; la conclusión a la que llega Dworkin, R. (1998) es que los principios orientan una decisión en un sentido cierto. 
Son numerosas las normas constitucionales invocables para reconocer todos los derechos laborales a los trabajadores del Estado sujetos al CAS. El artículo $1^{\circ}$ de la Constitución Política abre ese amplio espectro que fundamenta la posición de la investigadora, pues la defensa de la persona humana y el respeto a su dignidad son el fin supremo de la sociedad y el Estado. Se afecta la dignidad humana del trabajador del Estado que no es reconocido plenamente en dicha calidad y se le desconocen determinados derechos laborales, pues se le degrada respecto a los demás trabajadores del Estado a los que sí se le reconocen todos los derechos laborales, pese a que en muchos casos desarrollan funciones similares, ambas de carácter permanente. La inseguridad jurídica y la inestabilidad personal que trascienden de la renovación o no renovación del contrato administrativo de servicios en períodos tan cortos como son de treinta días, sume al trabajador en una situación insoportable, impropia de un estado y régimen de gobierno democráticos, máxime si la autoridad jurisdiccional y el máximo intérprete de la Constitución lo han dejado en el desamparo al no proporcionarle tutela jurisdiccional efectiva en estos casos.

El hecho de que se haya denominado contrato administrativo constituye una flagrante violación al principio laboral de primacía de la realidad, pues en esta relación contractual el objeto es netamente laboral y no civil o administrativo, como lo puede ser un contrato de locación de servicios personales o un contrato de otra índole que celebre una entidad administrativa.

Asimismo, las características impuestas mediante norma jurídica al contrato administrativo de servicios calificándolo como especial y transitorio, no resisten el menor análisis racional porque el término especial significa que es singular o particular y que no es común o general, siendo muy adecuado o propio para algo; y el término transitorio significa temporal, fugaz y perecedero. Pero lo especial no implica negar el derecho fundamental, que es lo más importante y esencial del asunto laboral y que se exterioriza en los principios mismos del derecho constitucional y del derecho laboral, del sistema de protección internacional de los derechos humanos y del hombre.
Lo fundamental no es susceptible de desconocimiento. Si existiese alguna nota de especialidad en el asunto, lo fundamental del mismo no podría dejarse de aplicar por este motivo. No se trataría de aplicar un test de igualdad a partir de lo especial de una situación, sino ex ante, a partir de la naturaleza laboral del contrato del régimen CAS, en el cual lo fundamental -que no es posible desconocer- es el reconocimiento y respeto de los derechos fundamentales laborales, de lo contrario su naturaleza labora carecería de utilidad y beneficio para el trabajador. Cuando la sentencia manifiesta que no es posible aplicar el test de igualdad porque se trata de contratos diferentes, está expresando un contrasentido, ya que son contratos laborales en los que hay que salvaguardar los derechos laborales fundamentales, como la misma sentencia reconoce, sin que quepa hacer distingos de cuáles derechos se les reconoce y cuáles no, pues las cargas y obligaciones del trabajador en el desempeño de su función son iguales, por lo que los derechos deben ser también iguales.

Como se puede apreciar, el CAS como régimen de contratación del Estado lleva ya muchos años, por lo que no puede ser transitorio. Asimismo, tratándose de una relación netamente laboral no puede menoscabar derechos laborales que todos los trabajadores deben gozar, máxime si el término alude a una actividad muy buena y excelente, por lo que no habría razón para perjudicar y desmejorar a quienes la ejercen, por lo que tampoco puede ser extraordinario. Por último, no es especial, pues lo apropiado aquí no está dirigido a beneficiar al trabajador sino a perjudicarlo singularmente, lo que contraría el carácter tuitivo del derecho laboral, que en este caso el mismo Estado desconoce pero sin embargo lo sanciona cuando se trata de los contratos sujetos a modalidad en la actividad privada, que vulneran el principio de primacía de la realidad.

Además del artículo $1^{\circ}$ de la Constitución Política, el artículo $2^{\circ}$ incisos 1. y 2., avalan la posición de la investigadora frente al desconocimiento de determinados derechos laborales del trabajador que presta servicios al Estado sujeto al CAS, porque se le reconoce el derecho a su libre desarrollo y bienestar, así como a la igualdad ante la ley y la prohibición de discriminación por cualquier motivo. 
Siendo que la limitación en el goce y ejercicio de determinados derechos laborales atentan contra el desarrollo y el bienestar del trabajador al servicio del Estado sujeto al régimen CAS, así como se le discrimina pues no goza ni ejercita los mismos derechos laborales que otros trabajadores al servicio del Estado, pese a cumplir funciones de carácter permanente y similares a otros trabajadores que sí gozan de todos sus derechos laborales.

A mayor abundamiento, el artículo $22^{\circ}$ de la Constitución Política consagra el trabajo como un deber y un derecho, base del bienestar social y un medio de realización de la persona. De donde desciende que el trabajador al servicio del Estado sujeto al régimen CAS cumple su deber laboral en clave de contribución al bienestar social, pero no goza de todos los derechos laborales como los demás trabajadores al servicio del estado, viendo así afectada su realización personal.

En la misma línea, el artículo $23^{\circ}$ de la Constitución Política dispone que el trabajo en sus diversas modalidades es objeto de atención prioritaria del Estado, por lo que ninguna relación laboral puede limitar el ejercicio de los derechos constitucionales ni desconocer o rebajar la dignidad del trabajador. El CAS limita los derechos laborales de los que el trabajador sujeto a dicho régimen debe gozar; $\mathrm{y}$ al hacerlo rebaja y desconoce su dignidad

Asimismo, el artículo $26^{\circ}$ de la Constitución Política dispone que en la relación laboral se respetan los principios de igualdad de oportunidades sin discriminación; carácter irrenunciable de los derechos reconocidos por la Constitución y la ley; e interpretación favorable al trabajador en caso de duda insalvable sobre el sentido de una norma. Evidentemente, la violación de estos principios es flagrante en el régimen CAS, pues no existe razón válida para que persista el régimen CAS, tanto más si el Estado ha reconocido y repuesto el goce de ciertos derechos laborales, manteniendo limitado su acceso a otros sin razón válida alguna, precisamente por ser irrenunciables; y en el supuesto negado que la norma legal que regula el CAS permita dudas insalvables, la Constitución ordena cómo superar dicho trance, interpretando favorablemente al trabajador dicha norma para darle un sentido beneficioso en favor del trabajador y no perjudicial, como ocurre hasta ahora.
Pero como afirma Sagüés, N. (1998) la suerte de la Constitución depende, en mucho, de su interpretación, de ahí la trascendencia que tiene la interpretación en la realidad del derecho, pues los resultados de la labor del intérprete serán muy diversos según la técnica que emplee; aun cuando esto no permite consentir las perversiones exegéticas ni los caprichos hermenéuticos, ya que algunos interpretan tratando de encontrar el sentido a partir de la norma misma; y otros interpretan construyendo ex profesamente una respuesta jurídica que a veces termina siendo política sectorial, que es cuando entonces resulta tramposa, por adecuarse a lo que el gobernante de turno prefiera, en lo que la historia y la doctrina constitucional conoce como el bastardeo de la Constitución. Precisamente, esta es la justificación de la investigación realizada, analizar y criticar las normas regulatorias del CAS y la interpretación constitucional del máximo intérprete de la Constitución sobre la materia, a fin de determinar si está conforme con el plexo de los valores y principios democráticos que ella consagra.

No se olvide que el derecho es la expresión del poder político y, aun cuando el derecho constitucional es la limitación de aquel, no está exento, de facto, de manipulación por la fuerza omnipresente $\mathrm{y}$ hegemónica del poder, en cuyo caso la interpretación judicial de la Constitución perdería su esencial rasgo de imparcialidad respecto de las partes del proceso, que es la única forma de imparcialidad que recusa, pues debe estar interesada en servir a los valores y principios constitucionales.

En la interpretación de la Constitución debe cuidarse la fuerza normativa de la ley fundamental, que no es otra cosa que su valor y vigencia sociológica y jurídica, que pone de manifiesto su idoneidad para encauzar la política nacional y el comportamiento de la sociedad, más allá de su vigencia formal.

El tema puede ser explicado desde un punto de vista según el cual en un Estado democrático y de derecho gobierna la Constitución, de la cual depende la justificación del poder, sin la cual el poder no está legitimado para mandar algo o exigir obediencia. Pero también puede intentarse explicar desde una posición diametralmente opuesta, en el sentido que la Constitución formal tiene que ajustarse a la 
realidad para que sea útil y tenga valor, pues los problemas de la realidad y los problemas constitucionales son expresión de kratos más que de jure. Claro que con esta posición la Constitución no ordenaría nada y más bien se subordinaría a la realidad.

Eclécticamente se podría pensar que la Constitución es condicionante y condicionada por la realidad que aspira encauzar, pues tiene que reconocer demarcaciones, presupuestos y posibilidades fácticas de toda índole, tales como, económicas, políticas, históricas, técnicas, sociales, fácticas, entre otras, a fin de mantener su pretensión de vigencia. Sin embargo, se impone desde nuestro punto de vista la conciencia general y de las autoridades competentes en materia constitucional de respetar y cumplir con la Constitución, para hacer realidad lo que ella consagra. Se impone una especie de voluntad constitucional.

Esta dicotomía que afecta el sentido interpretativo, es posible de dilucidar optando racionalmente entre la constitución histórica, estatua o testamento, y la constitución viviente y actual, pero la elección dependerá de lo que el constituyente actual, esto es, el pueblo presente, decida partiendo de lo que la constitución formal reconoce y consagra.

Así, la interpretación judicial de la Constitución puede ser práctica si es apta para responder de modo provechoso a la sociedad y el sistema político democrático, resolviendo los problemas y no para mantenerlos irresolubles o agravarlos; puede ser creativa, siempre que desenvuelva y despliegue los valores y principios constitucionales a los casos que merecen su pronunciamiento; puede ser previsora, lo que supone que se identifique la norma constitucional aplicable y mida los resultados y verifique las consecuencias, hasta encontrar una interpretación adecuada; y puede ser política, no en el sentido partidario del término, sino de política arquitectónica y no de política agonal, para graduar las competencias del Estado con los derechos y libertades de las personas, en este caso, los trabajadores.

El verdadero peligro es el de la mutación constitucional por efecto de la interpretación, como apunta Sagüés, N. (1998), porque termina en la modificación indirecta o tácita de la Constitución, es decir, se cambia el sentido, aun cuando no el texto de la Constitución formal, por acción del derecho consuetudinario o judicial constitucionales o por normas parlamentarias y del Poder Ejecutivo, que se oponen a la Constitución, de donde resulta una impostura y no una complementación.

Si bien existe una necesidad de actualizar las normas constitucionales a la realidad actual, la acción correspondiente no debe estar exenta de contenido ético. En primer lugar, si en la realidad se han producido transformaciones socio políticas respecto de la situación que sirvió de base para elaborar la Constitución formal, la interpretación no debería limitarse a aplicar automáticamente la norma constitucional, sino buscar su adaptación y ajuste a la realidad, de esa manera evoluciona y se transforma sin perder el paso a la realidad, con el consiguiente ahorro de las reformas constitucionales formales.

Empero, considero que esta labor debe presidirla el pueblo, que es el constituyente actual, que debe ser convocado en consulta popular al efecto, para evitar que el intérprete analice, conciba y termine aplicando de modo diferente y de espaldas a la voluntad popular, pues si se trata de modificar tácita o indirectamente la Constitución, esa tarea le corresponde al constituyente en quien reside el poder y la soberanía popular.

Una interpretación democrática de la Constitución es el mejor instrumento, en juicio de la investigadora, para resolver una situación de afectaciones a la dignidad y los derechos fundamentales de las personas, desagraviando y devolviendo las esperanzas de la sociedad. Más aún, si no hubiere consenso, el juez constitucional supremo intérprete de la Constitución debe preferir la justicia, pues no está bien que ningún juez busque preferentemente la aprobación y el beneplácito general. De esa manera la decisión tendrá legitimidad axiológica.

Lo anterior no obstante, en el caso materia de investigación, no existe una contradicción entre las normas jurídicas constitucionales y los principios y derechos laborales, sino entre las reglas jurídicas que crean y regulan el CAS $\mathrm{y}$ dichos principios y derechos fundamentales en el ámbito laboral. 


\section{CONCLUSIONES}

Constitucionalmente, el Estado peruano es la única e indivisible organización jurídica y política de la sociedad nacional; y es democrático, social, independiente y soberano; es decir, se fundamenta en los valores democráticos, tales como, el respeto y defensa de la dignidad de la persona humana y de sus derechos fundamentales, como la libertad, igualdad, todos los derechos civiles, políticos, económicos, sociales y culturales; y entre sus deberes está garantizar la plena vigencia de los derechos humanos, promover el bienestar general que se basa en la justicia.

En esa línea de principios y valores democráticos que consagra la Constitución Política del Estado, el trabajo es un deber $\mathrm{y}$ un derecho para toda persona, por ser un medio de su realización y base del bienestar social, por lo que es objeto de su atención prioritaria; de ahí que ninguna relación laboral pueda limitar el ejercicio de los derechos constitucionales ni desconocer o rebajar la dignidad del trabajador.

Es tal la protección constitucional del trabajador que se debe respeto a los principios de igualdad de oportunidades sin discriminación; carácter irrenunciable de los derechos constitucionales y legales; interpretación favorable al trabajador en caso de duda insalvable sobre el sentido de una norma; así como se le protege adecuadamente contra el despido arbitrario; y reconoce los derechos de sindicación, negociación colectiva y huelga.

El Contrato Administrativo de Servicios (CAS) es un contrato de naturaleza laboral, que vincula a un empleador, que es el Estado, con un trabajador, para la prestación de su trabajo personal, con base en las notas características de subordinación y dependencia, a cambio de una contra prestación remunerativa.

Dicho contrato por su esencia laboral debe conllevar para el trabajador al servicio del Estado, el pleno goce y ejercicio de todos los derechos constitucionales y legales propios de la relación laboral, sin excepción alguna.

El carácter especial que la ley le otorga al CAS, que se define como diferente de lo común y pensado o destinado para un determinado fin, persona o cosa específica; no significa por ello que pueda vulnerar los derechos constitucionales y legales laborales, por cuanto la norma fundamental del Estado les da un reconocimiento supremo y un tratamiento de protección contra todo acto o norma que pretenda desconocerlos.

El propio Estado, constituido con base en los principios rectores de su Constitución Política, no puede desconocer dichos derechos laborales. La especialidad contractual laboral, en este caso, puede atender a fines o cosas concretas, mas no puede desvincular a la persona del trabajador de sus derechos ínsitos a toda relación laboral en el Perú, por ser éstos de mayor nivel en la misma norma jurídica constitucional y en el derecho natural.

No es posible sostener razonablemente, sin que se vea afectado el principio democrático de igualdad, que el Estado cree una oportunidad de trabajo con el CAS, pero que el contrato laboral no reconozca ciertos derechos constitucionales y legales de toda relación laboral, más aún si el empleador es el mismo, las funciones tienen carácter permanente y son desempeñadas por trabajadores sujetos a regímenes laborales distintos que confieren diferentes derechos laborales, con notorio y grave perjuicio para el trabajador CAS.

La normatividad del régimen especial denominado Contrato Administrativo de Servicios, transgrede la igualdad, que es un principio y un valor democrático, así como un derecho constitucional laboral, la misma que se ve afectada, porque desconoce ciertos derechos laborales del trabajador sujeto a dicho régimen, constituyendo un menoscabo de su dignidad.

La normatividad del régimen especial denominado Contrato Administrativo de Servicios, afecta la libertad de trabajo, rebajándola y limitándola, ya que la necesidad apremiante de contar con un trabajo, obliga a la persona humana a celebrar un contrato laboral bajo el régimen CAS con notorio detrimento de sus derechos, tales como la compensación por tiempo de servicios, la gratificación por fiestas patrias y navidad, bonificación de escolaridad, asignación familiar, la estabilidad laboral y la protección contra el despido arbitrario.

El CAS transgrede el derecho a la estabilidad laboral, porque es de carácter temporal y, en esa medida, su duración es mensual y renovable hasta un año fiscal, situación que 
impide el desarrollo laboral del trabajador estatal, así como su acceso a la Carrera Pública, lo que evidencia una inseguridad en la relación laboral y una discriminatoria falta de oportunidad laboral.

Afecta y limita la tutela resarcitoria en la relación laboral, porque la indemnización por despido arbitrario está restringida a tres remuneraciones, nivel por debajo del reconocido a un trabajador estatal sujeto a otros regímenes laborales.

Niega la tutela restitutoria en la relación laboral por cuanto reglamentariamente no está amparada la pretensión de reposición, derecho que sí tienen los trabajadores públicos sujetos a otros regímenes laborales.

Viola el principio laboral de continuidad porque al ser un contrato temporal perjudica la estabilidad laboral, niega la posibilidad de un vínculo perdurable y una vocación de establecer una relación laboral duradera, de duración prolongada en el tiempo, pese a la función permanente que cumple el trabajador y que constituye precisamente el fundamento material de la continuidad, pero que en el régimen CAS se disimula afectando la realidad.

Asimismo, viola el principio de razonabilidad porque desempeñando funciones permanentes, como los trabajadores estatales sujetos a otros regímenes laborales, no se le reconoce al trabajador sujeto al CAS los mismos derechos, siendo que a igual razón debe corresponder igual derecho.

Desnaturaliza el contrato de trabajo porque el trabajador sujeto a este régimen puede estar prestando servicios durante más de cinco años y seguirá siendo considerado por el Estado como empleador, como un trabajador temporal.

El hecho que la Ley $N^{\circ} 29849$ establezca la eliminación progresiva del régimen CAS, no regulariza la indemnidad de los derechos laborales afectadosnireivindica lamenoscabada dignidad del trabajador, porque no reconoce devengados ni dispone la retroactividad laboral benigna del reconocimiento de los derechos laborales afectados que dejan de estarlo, violando el principio de irrenunciabilidad de los derechos laborales

La Ley $\mathrm{N}^{\circ} 29849$ dispone la eliminación gradual del CAS, sin embargo han transcurrido más de cinco años de vigencia y se comprueba que el índice de trabajadores públicos sujetos a dicho régimen, no acredita el cumplimiento de dicho mandato, pues según el Informe a Abril de 2012 de la Autoridad Nacional del Servicio Civil, los trabajadores CAS constituyen el 17\% del total de servidores públicos, siendo la segunda fuerza laboral del Estado, después de las carreras especiales, conformadas por militares, policías, magistrados, diplomáticos, magisterio y salud; y antes de los trabajadores sujetos al régimen del Dec. Leg. No 276. Peor aún, de acuerdo con la información de la Autoridad Nacional del Servicio Civil, aparecida en el Diario Gestión de 11 de julio de 2017, la contratación CAS concentra el $40 \%$ del empleo público, seguido del régimen de carrera pública con $38 \%$ (D.L. $\mathrm{N}^{\circ} 276$ ) y la contratación por el régimen privado con $22 \%$ (D.L. $\mathrm{N}^{\circ} 728$ ), por haber crecido en los últimos cinco años de 148,344 trabajadores en el 2011 a 275,140 al 2016 , es decir, crecieron en un $8 \%$ anual, en promedio, y $76 \%$ acumulado.

El incumplimiento de Ley $\mathrm{N}^{\circ} 29849$ demuestra la falta de voluntad del propio Estado de no cumplir con las disposiciones del Tribunal Constitucional, ya que este temporal se perpetúa en el tiempo, desconociendo los derechos laborales, constituyendo un obstáculo para la reforma del servicio civil y la meritocracia en el Estado peruano, así como dejando subsistente el principal problema del empleo público, que son los quince regímenes laborales del Estado, lo que supone la coexistencia de servidores públicos con diferentes condiciones en ingreso al servicio, estabilidad, despido, disciplina, derechos y obligaciones diferentes, incluso dentro de una misma entidad.

No es razonable jurídicamente ni legítimo democráticamente un régimen laboral especial para que el Estado peruano contrate personal en condiciones diferentes de perjuicio, a las que se encuentra el personal de servidores y funcionarios públicos, por cuanto el Estado debe atender preferentemente a la realización de la persona humana y el respeto y protección de sus derechos fundamentales, entre los que se cuenta el trabajo.

El CAS trasgrede también el principio de Primacía de la Realidad porque lo que ocurre en la práctica es que el trabajador estatal 
desarrolla una labor permanente con las mismas responsabilidades y obligaciones que un trabajador público sujeto a otro régimen laboral y, sin embargo, no tiene todos los derechos de éste, pese a que la función es permanente pero el contrato es temporal.

Es inválida una regla de derecho que transgrede los principios jurídicos, los valores democráticos y los derechos constitucionales laborales en perjuicio de un trabajador estatal sujeto al Contrato Administrativo de Servicios, porque la Constitución Política consagra la irrenunciabilidad de los derechos laborales; la imposibilidad jurídica de que una relación laboral limite el ejercicio de los derechos laborales y desconozca la dignidad del trabajador; el principio de igualdad de oportunidades sin discriminación; y la interpretación favorable al trabajador en caso de duda insalvable sobre el sentido de una norma.

Es indebido que una regla de derecho predomine sobre un principio jurídico, un valor democrático y un derecho constitucional laboral, como ocurre en el CAS, porque son estos criterios rectores los que deben inspirar e informar el contenido de las reglas y normas del ordenamiento legal, conforme a una interpretación sistemática de los preceptos constitucionales y a la forma de estado democrática que la propia Constitución Política declara.

\section{FUENTES DE INFORMACIÓN}

\section{Fuentes bibliográficas}

Alexy, Robert: "Sistema jurídico, principios jurídicos y razón práctica”, en Doxa.Cuadernos de Filosofía del Derecho, núm. 5, 1988.

Álvarez González, N. (1999) "Hacia una teoría crítica de la dignidad humana" Alcalá, Universidad.

Bidart, Germán (2002) “Lecciones elementales de política" Décimo primera edición. EDIARSociedad Anónima Editora Comercial, Industrial y Financiera. Buenos Aires, Argentina.

Cabanellas, Guillermo (1972) en Diccionario de Derecho Usual. Editorial Heliasta S.R.L Buenos Aires- Argentina.
Carrasco, Luciano y Torres, Germán (2006) en Aplicación Práctica de los Derechos Laborales. Editorial Santa Rosa S.A. Lima Perú.

Carruitero Lecca, F. y Lujan, M. (2005) en Filosofía del Derecho: Positivismo Jurídico. Ediciones Jurídicas. Buenos Aires- Argentina

Congreso de la República del Perú (2013) "Constitución Política del Perú" Edición del Congreso de la República, Oficialía Mayor, Oficina de Participación, Proyección y Enlace con el ciudadano.

De los Heros, Alfonso (2004) en Los Contratos de trabajo de duración determinada: ¿Regla o Excepción? en Los Principios del Derecho del Trabajo en el Derecho Peruano- Libro homenaje al profesor Américo Pla Rodríguez. Sociedad Peruana de Derecho del Trabajo y de la Seguridad Social (Comité Editor) Carlos Blancas Bustamante, Guillermo Boza Pró y Fernando García Granara, Lima- Perú.

De Trazegnies, Fernando. En La Muerte del Legislador (2004) en Selecciónde Lecturas de Filosofia del Derecho. Francisco Carroitero Lecca (compilador) Jurista Editores E.I.R.L, Lima- Perú

Durkheim, Ronald (1998) "Los derechos en serio" Ariel, Barcelona.

Gutiérrez Gutiérrez, Ignacio (2005) "Dignidad de la persona y derechos fundamentales" Marcial Pons Ediciones Jurídicas y Sociales S.A., Madrid.

Habermas, Jurgen en diálogo con Ronald Dworkin (2004) en Selección de Lecturas de Filosofia del Derecho. Francisco Carruitero Lecca (compilador) Jurista Editores E.I.R.L, Lima- Perú

Hart, H.L. (2004) en el Positivismo y la independencia entre el Derecho y la Moral, en Selección de Lecturas de Filosofía del Derecho. Francisco Carruitero Lecca (compilador) Jurista Editores E.I.R.L, Lima- Perú

Huamán Ordoñez, Luis (2012) en $C A S$. El contrato administrativo - laboral especial de servicios. Grijley E.I.R.L, Lima -Perú 
Should the rule of law prevail over the labor legal principle?

Analysis of the administrative contract of services.

Kelsen, Hans "¿Qué es el positivismo jurídico?" en Revista de la Facultad de Derecho de México $\mathrm{N}^{\circ}$ 61. Disponible en https://revistas-colaboracion.juridicas.unam. $\mathrm{mx} / \mathrm{index} . \mathrm{php} / \mathrm{rev}$-facultad-derecho-mx/ article/view/26290/23671

Neves, Javier (2000) en Introducción al Derecho Laboral en Colección Textos UniversitariosPontificia Universidad Católica del Perú. Fondo Editorial PUCP, Lima- Perú.

Plá Rodríguez, Américo (1978) en “Los Principios del Derecho del Trabajo”. De Palma, 2da Ed. Actualizad. Bs Aires.

Plá Rodríguez, Américo en Principio de la Razonabilidad (2006) en Los Principios del Derecho del Trabajo en el Perú. Luis Nava Guibert. Corporación Grafica Navarrete S.A, Lima- Perú

Sagüés, Néstor Pedro (1998) “La interpretación judicial de la Constitución" Ediciones Depalma, Buenos Aires.

Smend, Rudolf (1985) "Constitución y Derecho constitucional" CEC, Madrid.

Toyama, Jorge y Vinatea, Luis (2011) en Guía Laboral para Asesores Legales, Administrativos, Jefe de Recursos Humanos y Gerentes. Gaceta Jurídica. S.A, Lima- Perú.

\section{Fuentes hemerográficas}

García, Álvaro (2010) en ¿Cómo se está aplicando los Principios Laborales en el Perú? Un Enfoque teórico- jurisprudencial. Gaceta Jurídica S.A, Lima- Perú.
Paredes, Brucy (2014) en Dictámenes de la Autoridad Nacional del Servicio Civil en Soluciones Laborales $N^{\circ}$ 74. Gaceta Jurídica S.A. Lima- Perú.

Quispe, Gustavo. (2010) en Preguntas y respuestas sobre Contrato Administrativo de Servicios en Soluciones Laborales. Gaceta Jurídica S.A, Lima -Perú.

\section{Fuentes electrónicas}

Declaración de los derechos y deberes del Hombre y del ciudadano de Francia (1789). Disponible en: https://democraciaparticipativa. net/documentos-data-a-referenda/documentosen-espanol/documentos-sobre-derechoshumanos/10371-declaracion-de-los-derechosdel-hombre-y-del-ciudadano-1789.html

Sentencia del Pleno del Tribunal Constitucional de 08 de mayo de 2013 recaída en el expediente $\mathrm{N}^{\circ}$ 00014-2012-PI/TC. Disponible en:

h t t p : / / w w w jurisprudencia/2013/00014-2012-AI.pdf

Informe de la Autoridad Nacional del Servicio Civil. Disponible en:

http://storage.servir.gob.pe/biblioteca/ SERVIR\%20-\%20E1\%20servicio\%20 civil\%20peruano\%20-\%20Anx1.PDF 